\title{
En busca de un destino cumplido: el padre Eusebio del Niño Jesús O.C.D. y su defensa de la voz pura de Santa Teresa ${ }^{1}$
}

\author{
Amelina Correa Ramón \\ Universidad de Granada
}

Título: En busca de un destino cumplido: el padre Eusebio del Niño Jesús O.C.D. y su defensa de la voz pura de Santa Teresa.

Resumen: Se rescata aquí la figura del P. Eusebio del Niño Jesús (1888-1936), carmelita descalzo de formación intelectual y final muy trágico, que luchó denodadamente por reconducir lo que juzgaba excesos interpretativos del espiritismo acerca de la fundadora del Carmelo, para restablecer, en suma, la voz pura de Santa Teresa.
Title: In Search of a Fulfilled Destiny: Father Eusebio del Niño Jesús O.C.D. and his Defense from the Pure Voice of Santa Teresa.

Abstract: The following paper intends to revive the figure of P. Eusebio del Niño Jesús (18881936), an educated discalced Carmelite who had a very tragical ending and who fought intrepidly to redirect what he considered to be interpretative excesses of spiritualism regarding the founder of the Carmelite convent, in order to reestablish, basically, the pure voice of Teresa of Ávila.

Key words: P. Eusebio del Niño Jesús, Discalced Carmelite, Teresa of Ávila, Spiritualism, Spiritism

Date of Receipt: 5/12/2019.

Date of Approval: 15/12/2019.

\section{Hacia el Convento de Carmelitas Descalzos de Toledo}

"Corre el tren / por los brillantes rieles, / devorando matorrales, / alcaceles, / terraplenes, pedregales. / [...] Marcha el tren. El campo vuela”. Así, en

1 Este artículo se enmarca en el Proyecto I+D "La conformación de la autoridad espiritual femenina en Castilla”, Ref.FFI2015-63625-C2-2-P, financiado por el Ministerio de Economía y Competitividad y por los Fondos FEDER. 
plena evocación machadiana, discurría mi viaje a la imperial e histórica ciudad de Toledo en una temprana y muy cálida tarde del otońo de 2017. Desde Madrid, y en un veloz ferrocarril muy distinto en todo de esos vagones en cuyos asientos de madera recorriera el poeta sevillano tantos kilómetros del "ara gigante" de la "tierra castellana" que cantara su dilecto Unamuno, yo entretengo el rápido trayecto con la lectura de bibliografía para la investigación que tengo entre manos, y cuyo objeto me conduce a la que no en vano ha sido considerada tradicionalmente "Roma española".

"Toledo está por encima de cuanto se dice de ella. Dios la ha adornado como a una novia, ciñendo su cintura con un río parejo a la Vía Láctea y coronando su cabeza con ramas como estrellas". Tan evocadora cita de la ciudad que ahora es mi destino procede de un poeta árabe de época clásica y la recoge Miguel Gallego Zapata en un cuanto menos llamativo artículo que me entretengo en ojear, titulado "Toledo desde el Mar Menor"2 (Mar Menor por desgracia tan de actualidad, en el momento de escribir estas líneas).

El moderno tren de diseño aerodinámico me conduce a la antigua y venerable ciudad que fuera en tiempos morada de los carpetanos, como señala el historiador latino Tito Livio, quien relata la conquista de la ciudad en el año 192 a. C. por parte del cónsul Marco Fulvio Nobilior y le da por primera vez un nombre cercano al que hoy conocemos: Toletum, al parecer, latinización de otro anterior celtibérico.

Pues a ese lugar mítico, cruce de caminos y civilizaciones, centro de poder e irradiación de las más refinadas y nobles formas culturales, me dirijo con un afán investigador. Voy en busca de las huellas de un significativo personaje de nuestra literatura religiosa - aunque también en buena medida filosófica - de finales del XIX y comienzos del XX, el P. Eusebio del Niño Jesús, O.C.D., cuya vida efímera quedó bruscamente truncada en el frío pavimento de la calle el día 22 de julio de 1936.

El P. Eusebio del Niño Jesús (1888-1936) tuvo por nombre en el siglo el de Ovidio Fernández Arenillas y constituye el tercer eslabón de una fecunda cadena de relecturas teresianas en la que he empeñado varios años para intentar sacarlas a la luz desde el oscuro olvido en que se

2 Miguel Gallego Zapata, "Toledo desde el Mar Menor", Temas toledanos y estudios varios. XXXIII Congreso de la Asociación Española de Cronistas Oficiales, Córdoba, Real Asociación Española de Cronistas Oficiales/Fundación Prasa, 2008, pp. $27-43$ (p. 27). 
sumieron tras la brillante fulguración de unos años fecundos ${ }^{3}$. Así, habría que partir inicialmente del marco temporal de cuatro intensas décadas de efemérides carmelitanas, que ofrecen un innegable y casi paroxístico momento de auge de aproximación a la vida, la obra y la reasignación simbólica de Teresa de Jesús, enmarcadas entre dos hitos muy señalados: 1882, con la celebración del tercer centenario de su muerte, y 1922, año en cuyo mes de marzo se cumplía el tercer centenario de su canonización por el Papa Gregorio XV. Pero en esa etapa se incluían, además, otras dos fechas notables y seguidas, con el recuerdo en 1914 del tercer centenario de su beatificación por el Papa Paulo $\mathrm{V}$ y asimismo con los fastos de conmemoración del cuarto centenario de su nacimiento en 1915. Un extenso periodo, por tanto, de cuarenta años de intensificación teresiana, con cuatro marcados pilares, dos de índole biográfica, 1882 y 1915, y otros dos de naturaleza hagiográfica, 1914 y 1922.

Dentro de esas aproximaciones, acercamientos y revisiones de la figura y la obra de Teresa de Jesús me interesa precisamente uno muy concreto que surge en el seno de uno de los más llamativos movimientos ideológicos nacidos y extendidos al hilo de la crisis global de fin de siglo, como es el espiritismo. En ese ámbito, como he adelantado, se genera una cadena de relecturas de la santa de Ávila que culminan en la magna obra en dos volúmenes que entre 1929 y 1930 ve la luz bajo la firma del P. Eusebio.

Mi destino directo en este viaje otoñal a la ciudad castellana es el Convento de los Carmelitas Descalzos, donde voy a pasar varios días sumergida en el estudio de esa figura apasionante y que desempeña un papel muy directo en el trabajo de investigación en el que, como he dicho, llevo varios años inmersa. Allí se encuentra el máximo especialista, el P. José Vicente Rodríguez, sabio sacerdote carmelita de más de noventa años de edad, con quien he contactado previamente por correo electrónico, y que, confirmándome que en el convento conservan abundante documentación relacionada con el P. Eusebio del Niño Jesús, me invita amable y muy cordialmente a acudir allí durante los días que necesite y a disponer con plena libertad de cuantos escritos me sean precisos.

3 Para ver el análisis y estudio pormenorizado de dicha cadena de relecturas, cf. Amelina Correa Ramón, “Qué mandáis hacer de mí?" Una historia desvelada de relecturas teresianas en el contexto cultural de entresiglos, Madrid/Frankfurt, Iberoamericana Vervuert, 2019. 
Desde la preciosa y centenaria estación neomudéjar, el trayecto en taxi por la ciudad parece transportarme hacia atrás en el tiempo, hasta depositarme en una antigua zona de conventos y monasterios, radicada en una red de callejuelas que conservan aún los tradicionales cobertizos, zona no ajena, por cierto, a las leyendas de Gustavo Adolfo Bécquer, que tanto amara recorrer estas calles y escuchar sus voces del pasado. Finalmente asciendo por una cuesta que me deja en la Plaza de los Carmelitas Descalzos, ante el convento de dicha Orden religiosa. La fundación de este convento fue puesta bajo la advocación del Espíritu Santo y tuvo lugar el 16 de mayo de 1586, si bien es verdad que pasa por otros dos lugares previos hasta la ubicación definitiva que se conserva hoy en día ${ }^{4}$, con un edificio que no se iba a construir hasta los años 16431655, eligiéndose un lugar cerca de la Puerta del Sol y de la legendaria Mezquita del Cristo de la $\mathrm{Luz}^{5}$, en pleno centro de la ciudad ${ }^{6}$. El convento consta de un "claustro cuadrado en torno al cual se disponen las celdas y diversas estancias"7, e incluye una iglesia, de planta rectangular, para cuya portada -que, con toda probabilidad, parece haber sido la última parte en realizarse- se contrató "la obra de cantería al maestro Juan Ramos de la Vega", siguiéndose luego "las trazas y condiciones de [...] fray Pedro de San Bartolomé — carmelita y tracista de la orden—"

4 Aunque afectado por la Desamortización en 1835, el edificio "Fue devuelto a los PP. Carmelitas el 8 de junio de 1893, gracias al Cardenal Monescillo y la Duquesa de Villahermosa" "“Carmelitas Descalzos Provincia Ibérica”, https://www.ocdiberica. com/es/comunidad/43/ver, consultado el 29 de octubre de 2019).

5 Carlos Dueñas Rey, "El Cristo de la Luz", Enigmas y misterios de Toledo, Córdoba, Almuzara, 2017, pp. 61-65.

6 J. Carlos Vizuete Mendoza, "Lugares sagrados y órdenes religiosas. Monasterios y conventos en Toledo", en J. Carlos Vizuete Mendoza y Julio Martín Sánchez (coords.), Sacra loca toletana. Los espacios sagrados en Toledo, Cuenca, Ediciones de la Universidad de Castilla-La Mancha, 2008, pp. 157-187 (178-179).

7 Carlos Barrio Aldea y Bienvenido Maquedano Carrasco, "La huerta del Convento de Carmelitas Descalzos”, en Francisco Javier Sánchez-Palencia et al., Toledo, arqueología en la ciudad. Toledo, Servicio de Publicaciones de la Junta de Comunidades de Castilla La Mancha, 1996, pp. 269-273 (269).

8 Fernando Marías, La arquitectura del Renacimiento en Toledo (1541-1631). Tomo III. Madrid, Consejo Superior de Investigaciones Científicas, 1986, p. 58. 


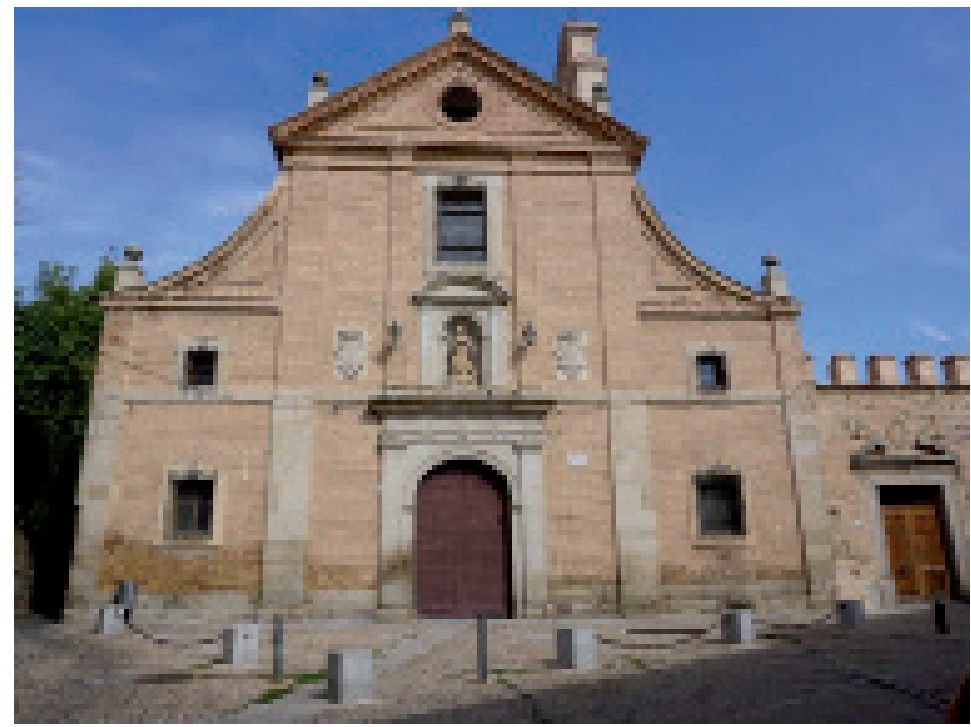

Portada del Convento de los Carmelitas Descalzos de Toledo

Gestionadas toda las cuestiones prácticas de “intendencia” de mi alojamiento gracias a la más que cordial eficacia del entonces Hermano Francisco Javier Moreno (hoy ya P. Francisco Javier de María), llego sobre las cinco de la tarde al gran portón; y a mi llamada, me abre el muy amable y tímido Hermano Eustaquio García Santiago, quien en breve me conduce a la habitación que se me ha destinado en el impresionante edificio, hoy reconvertido en austera pero confortable Casa de Espiritualidad, y por cuyos corredores y pasillos, antaño concurridos, hoy solo habitan la paz y el sosiego. Pronto llega a mi habitación, conducido por el Hermano Eustaquio, el propio P. José Vicente, muy llano y jovial, que compartirá conmigo sus abundantes conocimientos durante los días de mi estancia, además de depositar en mis manos, en ese momento liminar de mi llegada, todo el valioso material sobre el P. Eusebio del Niño Jesús que se ha conservado en el Convento del que era prior en el momento de su muerte. En la actualidad, el prior de la Casa es el P. Ricardo Plaza, que me recibe así mismo con toda hospitalidad, y del que cabe destacar su faceta como restaurador y artista, siendo licenciado en Bellas Artes por la Universidad de Granada. De este modo, su primor y cuidado estético se aprecian por todos y cada uno de los rincones del convento. 


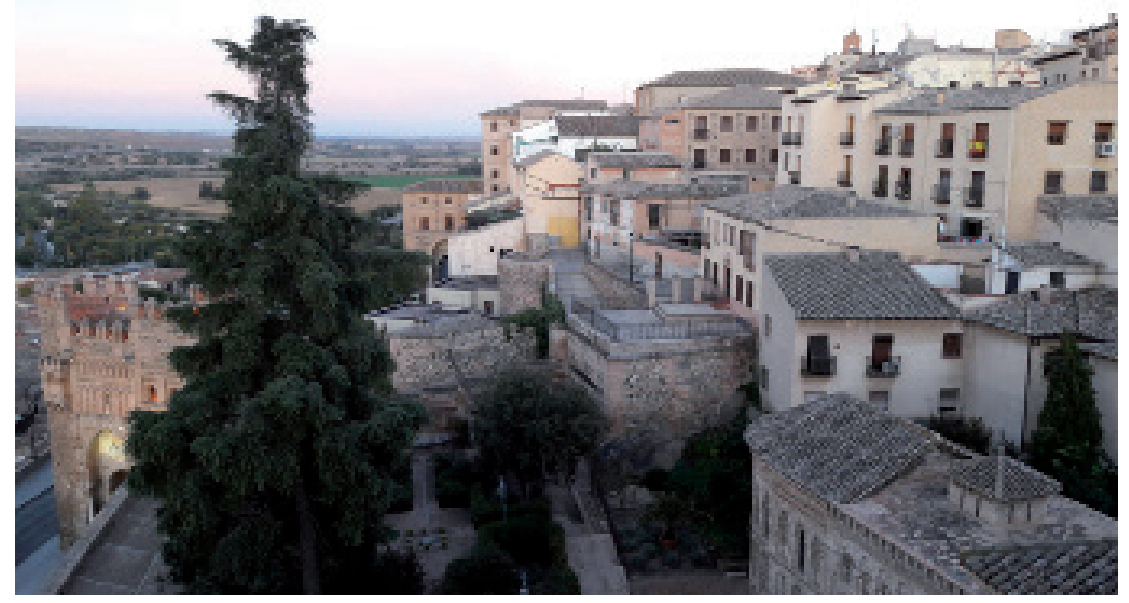

Vistas de Toledo desde la habitación, con la Puerta del Sol

$\mathrm{Si}$ ya he anticipado que durante los últimos años de mi quehacer investigador he prestado especial atención a la recepción teresiana, sobre todo centrándome en ese ya aludido momento de auge que la fascinación por la figura de la santa experimenta en el marco temporal comprendido entre 1882 y 1922, conviene comenzar aclarando que, si bien esas cuatro décadas se demostrarán muy fecundas en todo tipo de acercamientos teresianos, predominando las aproximaciones hagiográficas y canónicas, sin embargo, la complejidad del crítico periodo del tránsito entre el XIX y el XX posibilitará que se lleven a cabo también numerosas relecturas desde planteamientos mucho más heterodoxos y que incluso resultaron polémicos para la oficialidad católica al poner el acento en el cuerpo y no en el alma - en la erótica y no en la mística (recuérdense los casos de Charcot y sus estudios acerca de la presunta relación entre la histeria y la mística desde el punto de vista de la neuropsiquiatría o, centrándonos en el ámbito literario, de una obra que levantará polvaredas tras su estreno en París el 10 de noviembre de 1906, como fue La Vierge d'Avila (SainteThérèse), del escritor parnasiano Catulle Mendès, protagonizada por la estrella del momento, una diva de la altura de Sarah Bernhardt)—. 


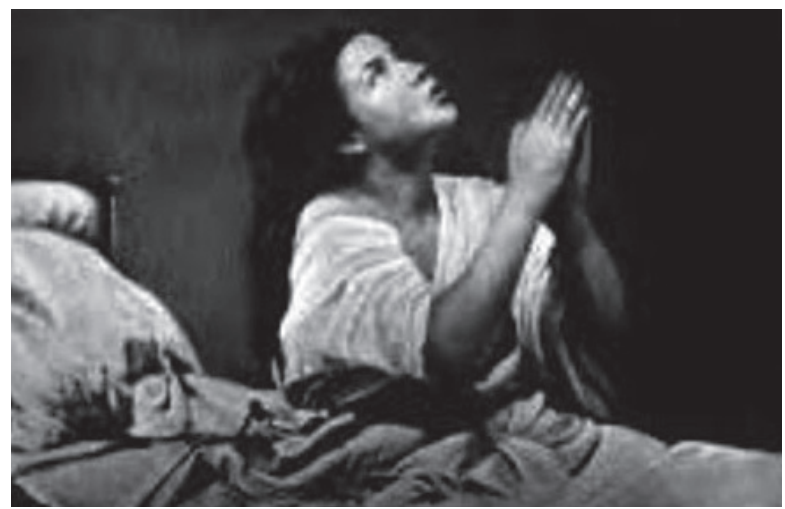

Paciente del Dr. Charcot para el estudio de la relación entre mística e histerismo

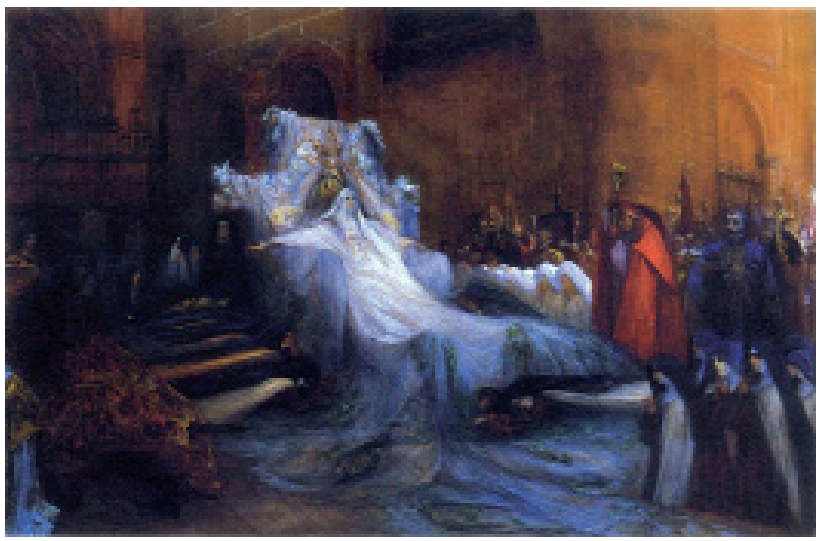

Georges Jules Victor Clairin(1843-1919), Sarah Bernhardt en la escena final de La Vierge d'Avila

También me interesa que entonces se empezó a releer a Teresa de Ávila y su mensaje a la luz del espiritismo: un nuevo credo muy difundido en la época, y con seguidores y practicantes ilustres (los principales y más conocidos sin duda están en la mente de todos los lectores iniciados en el misterio: Victor Hugo, Arthur Conan Doyle, pero también científicos prestigiosos como el naturalista Alfred Russel Wallace, decisivo en la formulación de la selección natural de las especies o el astrónomo francés Camille Flammarion, fundador de la Sociedad Astronómica Francesa), y que se presentaba, además vinculado con el anarquismo, feminismo, masonería, librepensamiento y otras tendencias disidentes, además de 
propugnar y defender con valentía una vuelta al cristianismo primitivo, con la recuperación del mensaje puro de Jesucristo.

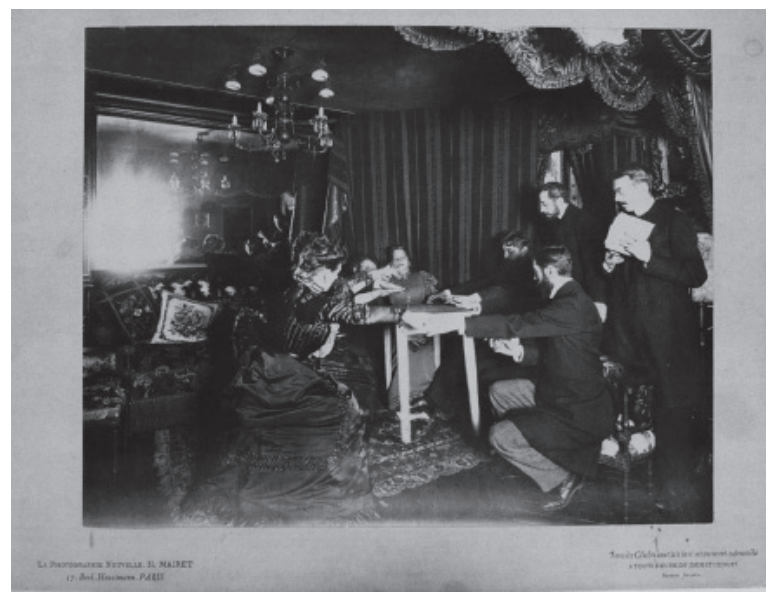

Sesión de espiritismo en casa del astrónomo Camille Flammarion, con la famosa médium Eusapia Palladino, noviembre de 1898

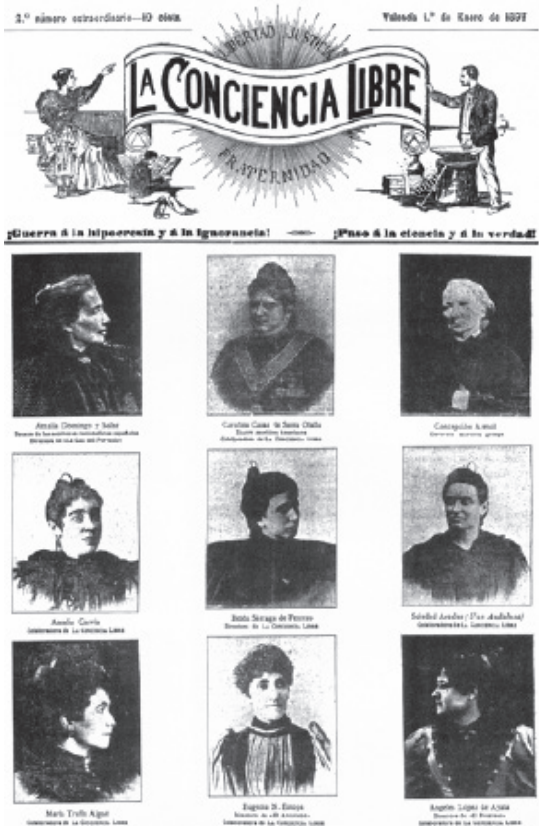

Revista La Conciencia Libre, Valencia, enero de 1897 
En este marco va a destacar en España por méritos propios la espiritista Amalia Domingo Soler, que, en el caso concreto que nos ocupa, la "reinterpretación” teresiana, publica ;Te perdono! Memorias de un espíritu (inicialmente por episodios entre 1897 y 1899 en la revista por ella dirigida, La Luz del Porvenir, y posteriormente, recogidos en volúmenes, publicados en 1904-1905, y que alcanzarán luego diversas reediciones), que contiene las supuestas revelaciones de la santa obtenidas a través de un médium y ofrece una transgresora versión de su reforma planteando la manipulación de su mensaje por parte de la Iglesia, con el fin de desactivar su evidente carácter subversivo. Tan heterodoxa propuesta alcanzará una exitosa vida editorial, y dará inicio a una cadena de notables y llamativas repercusiones intertextuales, representadas fundamentalmente por sendas obras del pintor y escritor malagueño José Blanco Coris, quien, siguiendo el camino abierto por Amalia Domingo, publicará en 1920 el librito titulado Santa Teresa, médium ${ }^{10}$, y del P. Eusebio del Niño Jesús, autor de la sorprendente obra Santa Teresa y el espiritismo ${ }^{11}$. Al estudio pormenorizado de dicha sorprendente cadena, que había permanecido por completo oculta y velada hasta la fecha, he dedicado mi libro "¿Qué mandáis hacer de mi?" Una historia desvelada de relecturas teresianas en el contexto cultural de entresiglos, aparecido hace escasamente unos meses.

Sin embargo, circunstancias de la vida que no vienen aquí al caso me hicieron no poder incluir en dicho volumen todo el potencial referente al P. Eusebio del Niño Jesús, a su figura y a su obra, quien luchó denodadamente por reconducir lo que juzgaba, sin duda, excesos interpretativos del espiritismo, para restablecer la voz pura de Santa Teresa. Y es por ello que decido ahora dedicar el presente artículo a mis investigaciones toledanas en torno a su importancia, guiada en todo momento por la sabia autoridad del P. José Vicente.

9 Amalia Domingo Soler, ;Te perdono! Memorias de un espiritu, Barcelona, Casa Editorial Carbonell y Esteva, 1904-1905.

10 José Blanco Coris, Santa Teresa, médium, Madrid, Reus, s. f. [1920].

11 P. Eusebio del Niño Jesús C. D., Santa Teresa y el Espiritismo. Primera parte: Mediumnidad teresiana, Burgos, Tipografía de El Monte Carmelo, 1929 y Santa Teresa y el Espiritismo. Segunda parte: Puntos cardinales del espiritismo, Madrid, Mensajero de Santa Teresa y de San Juan de la Cruz, 1930. 


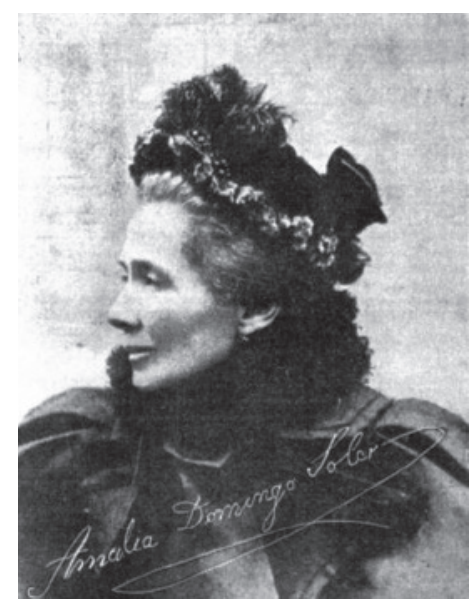

Fotografía de Amalia Domingo Soler

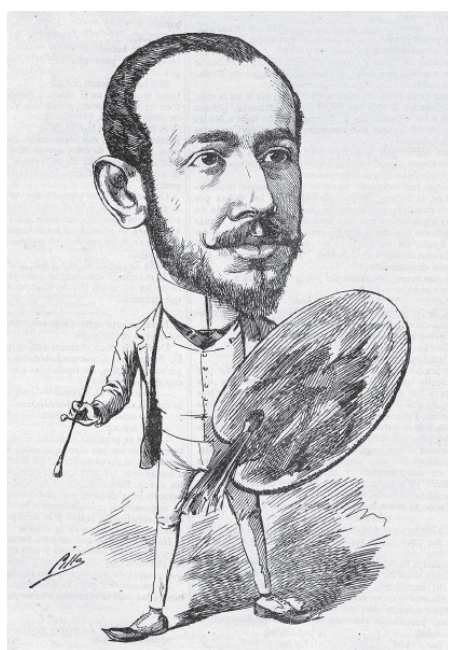

Caricatura de José Blanco Coris, firmada por “Cilla” (el famoso dibujante Ramón Cilla), en la portada de la revista Madrid Cómico, del 16 de abril de 1887.

\section{UNA VOCACIÓN FAMILIAR}

En Toledo habría de acabar abruptamente sus días, con tan sólo cuarenta y ocho ańos de edad, el 22 de julio de 1936 y siendo precisamente prior del Convento que la Orden tenía en la Ciudad Imperial — como ya he 
adelantado_- Ése es el motivo por el que en este cenobio se haya reunido y conservado tanta documentación en torno a este autor, sobre la que ahora volveremos. Pero antes de llegar a su final, remontémonos a los orígenes, para ver quién era este P. Eusebio del Niño Jesús, que nació como Ovidio Fernández Arenillas en una devota familia leonesa del pequeño pueblo de Castilfalé. Conviene señalar que hasta hace muy poco ${ }^{12}$ la única bibliografía donde se recogía su figura se encuadraba claramente en el ámbito religioso, lo que, en buena medida, no resulta extraño, dado que de un religioso se trata, y más aún, si se tiene en cuenta que desde hace unos años ha alcanzado oficialmente el rango de beato, en virtud de su trágico destino consumado en los primeros días de la Guerra Civil. Pero lo cierto es que el P. Eusebio, que contaba con una buena formación cultural y con indudables inquietudes intelectuales, fue también escritor, y en ese terreno dio a conocer numerosas obras, por lo que su faceta literaria merece ser de igual modo sacada a la luz y dada a conocer.

Su nacimiento como Ovidio Fernández Arenillas tendría lugar el 21 de febrero de 1888 en el seno de una familia numerosa radicada en el pequeño pueblo de Castilfalé Para intentar aproximarnos a la realidad que acompañaría los primeros ańos del futuro carmelita y escritor, podemos recurrir a la autoridad siempre fecunda del erudito viajero Pascual Madoz, quien hacia mediados del siglo XIX va a dedicar a esta localidad leonesa menos de treinta líneas en su monumental obra en varios volúmenes Diccionario geográfico-estadístico-histórico de España y sus posesiones de Ultramar. Madoz se refiere a este pueblo como Castil de Falé, nombre alternante durante mucho tiempo con el hoy ya fijado de Castilfalé — como ya se denominaba mayoritariamente en 1888 , fecha de nacimiento de nuestro protagonista-, situado al este de la provincia de León, a unos cincuenta kilómetros de

12 Se podría matizar que, de hecho, ha sido así hasta que yo adelanté brevemente en un primer artículo publicado en 2017 la importancia del P. Eusebio en el desvelamiento de esta historia literaria en torno a las relecturas finiseculares de Santa Teresa de Jesús (Amelina Correa Ramón, "Revisitaciones de Teresa de Jesús desde el otro lado: la doctora mística y el espiritismo finisecular”, Acta literaria, 54, junio, pp. 8398). Puesto que hasta la inclusión reciente de su figura en el Diccionario Biográfico Español publicado por la Real Academia de la Historia se lo tiene en cuenta tan solo en relación con su significación religiosa (María Encarnación González Rodríguez, "Fernández Arenillas, Ovidio. Beato Eusebio del Niño Jesús", Diccionario Biográfico Español, Madrid, Real Academia de la Historia, 2009, pp. 630-631). 
su capital, y perteneciente al partido judicial de Valencia de Don Juan. Se trata de un lugar de clima frío, cuyas enfermedades más comunes eran "tercianas, reúmas y algunas fiebres pútridas"13. En 1850 contaba con una casa consistorial que incluía cárcel y una "escuela de primeras letras dotada con 500 reales, a que asisten 60 niños de ambos sexos"14, además de una iglesia parroquial que databa del siglo XVI, consagrada a San Juan Degollado, con tres naves y espadańa, y que parece ser más que notable. El propio Madoz constata que en las cercanías de la localidad se encuentra una torre en precario estado de conservación, que habría pertenecido, al parecer, a una antigua iglesia, y que todavía existe en la actualidad.

Pascual Madoz, interesado, como bien se sabe, en dejar un registro lo más pormenorizado posible de todas y cada una de las localidades del país, añade también en su entrada información referente a los terrenos de la villa, "de mediana calidad" 15 , rodeada de encinas y robles, y cuya producción se basaba en los cultivos de trigo, centeno y cebada, y avena y viñas, aunque en menor cantidad, a los que habría que sumar de igual modo como medio de subsistencia la "cría de ganado lanar y caza de liebres y perdices" 16 .

En las fechas en que Madoz lleva a cabo su minuciosa recogida de datos y posterior publicación, Castilfalé era cabeza del Ayuntamiento de un municipio más extenso compuesto por varios núcleos poblacionales (Matanza de los Oteros, Valdemora, Valdespino Cerón y Villabraz, además del propio Castilfalé), con mil ciento setenta y cinco habitantes. Sin embargo, conviene subrayar que pocos años después estos diversos pueblos se fueron independizando, contándose en 1877 en el propio Castilfalé con una población de menos de cuatrocientos habitantes, que fue descendiendo paulatinamente hasta los menos de setenta con que cuenta en la actualidad. En realidad, todos estos pueblos constituyen, por desgracia, hoy en día buena muestra de lo que se ha dado en llamar la "España despoblada", como prueban los menos de ochenta habitantes

13 Pascual Madoz, Diccionario geográfico-estadístico-histórico de España y sus posesiones de ultramar, Tomo VI, Madrid, Imprenta del Diccionario geográfico-estadísticohistórico, 1850, pp. 168-169 (p. 168).

14 Ibidem, p. 169.

15 Ibidem.

16 Ibidem. 
que cuenta Valdemora, ciento diez Villabraz, o poco más de cincuenta Valdespino Cerón, que hoy día, junto con Zalamillas, está integrado en el municipio de Matanza de los Oteros.

De este modo, cuando Ovidio Fernández Arenillas vino a este mundo, llegaba a un pueblo que ha iniciado hace ya algún tiempo su decadencia, como prueban, no sólo esta comentada pérdida paulatina de habitantes, sino también, significativamente, la desaparición de un hospital que había venido funcionando entre los siglos XVII y XVIII y otra segunda iglesia, la de San Miguel, perdida en transcurso del siglo XIX, además de la ya aludida a la que pertenecen los restos de la torre que aún permanecen en pie, según consta en la información histórica que ofrece la página web de su Ayuntamiento ${ }^{17}$.

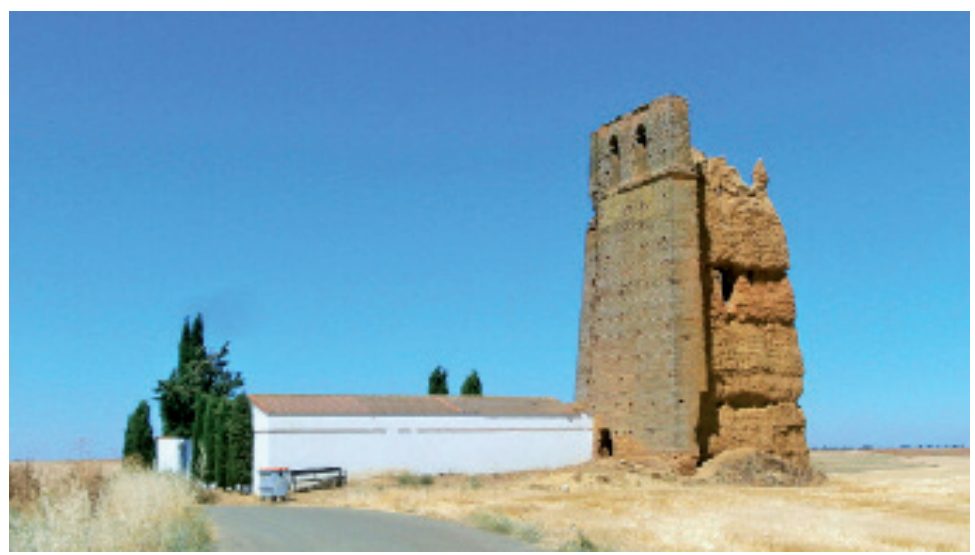

Restos de torre, junto al cementerio de Castilfalé

El pequeño Ovidio nacerá a las tres de la tarde del veintiuno de febrero de 1888 en el seno de una familia humilde y muy devota. Según consta en su inscripción en el Registro Civil del municipio ${ }^{18}$ — que debo agradecer a la amabilidad del personal del Ayuntamiento de la localidad-, Gregorio Fernández Valencia, “jornalero y labrador”, de treinta y nueve años de edad,

17 http://www.aytocastilfale.es/municipio/introduccion-historica/ [Consultado el 0809-2018].

18 Todos los datos consignados a continuación proceden de la certificación oficial expedida por el Ayuntamiento de Castilfalé, Registro Civil de Castilfalé, Sección 1a, Libro 3, Página 85, no 235. 
natural de Castilfalé, hace la inscripción del nacimiento al día siguiente de haberse producido en su domicilio de la calle Matanza, declarando que es hijo legítimo de él y de su esposa, Catalina Arenillas Ruano, de treinta y siete años, e igualmente natural del mismo municipio. Sus abuelos paternos, según consta en dicho documento oficial, fueron José Fernández y María Petra Valencia, por parte de padre, ambos difuntos, siendo los maternos Manuel Arenillas y Águeda Ruano Martínez.

El niño habría de ser bautizado cuatro días después, el 25 de febrero, en la mencionada iglesia parroquial de San Juan Degollado (que alude al mítico episodio bíblico de la decapitación del santo precursor por parte del rey Herodes, siguiendo los caprichosos designios de la voluptuosa Salomé, S. Marcos, 6, 17-28). Actuaron como sus padrinos Felipe Arenillas y Manuela Fernández, a los que cabría suponer respectivamente tíos materno y paterna del futuro clérigo y escritor.

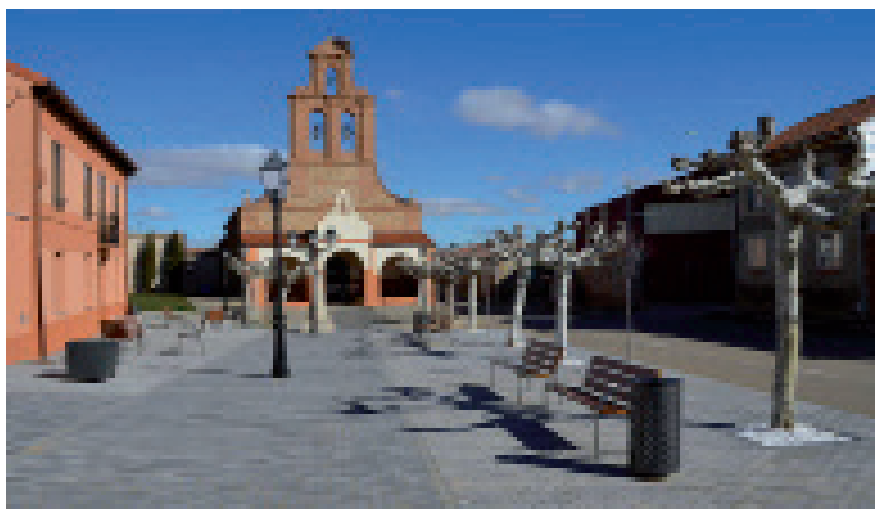

Iglesia de San Juan Degollado, Castilfalé

El poco frecuente nombre del neófito no coincide, como solía resultar habitual en casos de nombres bizarros o llamativos, con el del santo del día, ni del nacimiento, ni del bautizo. Y eso que, el 25 de febrero la Iglesia Católica conmemora a un santo, San Valerio del Bierzo (también conocido como San Valerio de Astorga), anacoreta del siglo VII cuya cercanía geográfica (Astorga dista poco más de setenta kilómetros de Castilfalé) podía haber influido a la religiosa familia en búsqueda de un modelo ejemplar para el recién nacido. Tampoco coincide el nombre elegido con el patrón local ni con ninguna devoción asociada a la localidad. Aunque 
se desconoce el motivo de la elección del nombre que se le impuso, lo cierto es que se constata que la muy numerosa familia se caracterizó precisamente por la originalidad de los escogidos para los siete vástagos que sobrevivieron a la infancia: Efigenia, Atanasio, Genoveva, Ursicino, el citado Ovidio, Mercedes y Prisciliano, tal y como recoge en su semblanza quien es hoy por hoy — como ya adelanté- el máximo especialista en la figura del autor, el P. José Vicente Rodríguez ${ }^{19}$. El menor, Prisciliano, ocho años más joven que su hermano Ovidio, y que lo seguirá también por la senda del Carmelo ${ }^{20}$, evocará años después el humilde pueblo en que ambos se habían criado, con sus restos de pasados esplendores, y su patrimonio legendario:

Hay un pueblecito pequeño, pobre, árido, sin árbol ninguno, escondido entre unas muy pendientes cuestas [...]. Está el pueblecillo como agazapado y recostado entre una gran cuesta al este, en cuya cima se levanta la torre, en otros tiempos muy sólida, desde la cual se puede ver no sólo la llanura que en semicírculo se explana delante de ella, sino varias leguas del contorno; y otra cuesta al oeste, donde está lo que siempre se ha llamado el Castillo, quizás porque era ya un castro de los antiguos [...]. Predominan allí las leyendas de moros y nombres de los mismos ${ }^{21}$.

La "escuela de primeras letras” a que aludirá Pascual Madoz iba a

19 José Vicente Rodríguez, La dichosa ventura. 16 carmelitas descalzos en Toledo, Madrid, Editorial de Espiritualidad, 2007, p. 30.

20 En efecto, Prisciliano profesará de igual modo en la Orden Carmelita, con el nombre de Valentín de San José, bajo el que se encuentran firmados sus textos. La narración biográfica sobre su hermano a la que pertenecen los fragmentos aquí recogidos fue incluida en el volumen globalmente titulado Esos, vestidos de blanco, ¿quiénes son?, en el que el P. José Vicente Rodríguez (que firma la "Presentación", aunque ejerce también como editor), reúne por primera vez dicho texto, junto con la "Semblanza de los 16 mártires carmelitas descalzos de Toledo", firmada por Father Herrera, O. C. D.; dichas estampas habían ido apareciendo inicialmente, entre 1963 y 1967, en la publicación Nuestros Venerables. Hoja oficial informática de las Causas de los Carmelitas Descalzos de Castilla.

21 San José, Valentín de, O. C. D., "Biografía de mi hermano Ovidio (Eusebio del Niño Jesús)", Father Herrera-Valentín de S. José, Esos, vestidos de blanco, ¿quiénes son?, Madrid, Editorial de Espiritualidad, 2005, pp. 109-129 (p. 111). 
desempeñar un papel decisivo en la vida del niño Ovidio Fernández, sobre quien D. Elías Reyero, "un maestro extraordinario"22, en palabras de su hermano Prisciliano, ejercerá una importante influencia. De hecho, en casa del propio maestro acostumbrará a reunirse una improvisada tertulia cotidiana en las noches de invierno, donde acuden diversas familias del pueblo; entre ellas, la del pequeño Ovidio, lo que cobra especial importancia si se tiene en cuenta lo relativamente aislado del pueblo, debido a la falta de comunicaciones. Según añade su hermano menor, la otra influencia destacable en su infancia va a ser la del párroco de su infancia, D. Lorenzo de la Vega, "modelo de sacerdote celoso, edificante y desinteresado" 23 . Conviene tomar en consideración este poderoso influjo, lo que, unido al ya mencionado carácter muy religioso de la familia, habría condicionado el que, de los siete hijos, nada menos que cinco entraran en religión, quedando tan sólo en el pueblo para hacer compañía a los padres dos de ellos: Ursicino y Mercedes.

En este sentido conviene señalar otro tercer factor, de influencia decisiva, que se encontrará en la vecina localidad de Grajal de Campos, distante de Castilfalé menos de cincuenta kilómetros. La villa más antigua del reino de León es una localidad igualmente caracterizada por un pasado mucho más próspero, que contó durante la Edad Media con un Hospital de Peregrinos, y que en el siglo XVI vería edificar un castillo artillero y el palacio renacentista de los Condes de Grajal. A eso habría que sumar un convento de franciscanos construido a finales de esa misma centuria, hacia 1599, y que, por encontrarse abandonado, iba a ser elegido seis años antes del nacimiento de nuestro protagonista, en 1882, para la fundación de un convento de Carmelitas Descalzas ${ }^{24}$,

\section{Ibidem, p. 112.}

\section{Ibidem.}

24 Paradojas del destino, andando el tiempo, esa comunidad de monjas carmelitas descalzas acabaría abandonando Grajal de Campos (alegando tanto diversos motivos de salud de las Hermanas, ya mayores, como de salubridad del propio edificio) y trasladándose finalmente en el año 2006 al abandonado Convento de las Capuchinas en la misma ciudad de Toledo en que el P. Eusebio había encontrado la muerte setenta años antes (https://www.elnortedecastilla.es/ prensa/20060929/valladolid/carmelitas-convento-grajal-campos_20060929.html [Consultado el día 14-11-2019]). Tras trece años allí, en julio de 2019 optaron por trasladarse de nuevo, aunque sin salir de la ciudad, para instalarse en el convento 
lo que tendría gran repercusión en los contornos. Además, el párroco anterior al citado Lorenzo de la Vega había sido, al parecer, capellán del convento y mantuvo una buena relación tanto con su fundadora, la Madre Adelaida de Santa Teresa, como con toda la Comunidad. Según parece, esta cercanía ocasionó la abundancia de vocaciones religiosas en Castilfalé, entre ellas las procedentes de la familia Fernández Arenillas, ya que inicialmente los cinco hermanos profesaron en la Orden Carmelita, si bien la hermana mayor, Efigenia, "no pudo continuar por falta de salud e ingresó más tarde en el Instituto de Apostolinas, donde perseveró hasta la muerte acaecida en Cienfuegos, en Cuba"25.

La familia Fernández Arenillas parece haber cultivado estrechos vínculos entre sus miembros, pero sin duda el más profundo de todos parece haber sido el que unió a Ovidio con su hermano menor Prisciliano, con quien mantendrá a lo largo de los años una frecuente y más que cordial correspondencia que evidencia que, a pesar de la distancia física ocasionada por sus respectivas vocaciones, a mbos se sintieron siempre unidos y próximos de corazón. Se puede destacar que en este amplio epistolario se encuentran frecuentes alusiones a sus otros hermanos, y en concreto llama la atención su preocupación con respecto a la mayor, Efigenia, de quien todos los datos que poseemos parecen indicar que habría padecido problemas de salud desde joven. Tanto es así que, por ejemplo, estando destinado el P. Eusebio en Cuba — como luego se verá-, en una carta a su hermano fechada el 24 de agosto de 1926, desde Camagüey, relata que ha podido ir a visitar a Efigenia, en la ciudad de Cienfuegos, y que la ha encontrado "muy buena, me pareció que estaba algo más llena que otras veces" 26 .

Llegados a este punto, conviene ahora explicar cómo y en qué circunstancias se ha conservado tanto este epistolario enviado por el P. Eusebio a su hermano menor, como a otros corresponsales (que incluyen algunas hijas espirituales y otros diversos compañeros), así como una extensa

que había fundado Teresa de Jesús en la Ciudad Imperial, cerca de la Puerta del Cambrón (https://www.latribunadetoledo.es/Noticia/Z0854B7CE-0906-4BF0F6E57D1214AFF981/201907/El-convento-de-las-Capuchinas-se-queda-hoy-sinmonjas [Consultado el día 14-11-2019]).

25 Valentín de San José, op. cit., p. 113.

26 Proceso de Beatificación de los Mártires Carmelitas Descalzos deToledo. Escritos, Volumen I: Epistolario, Texto mecanografiado, s. 1., s. f., p. 59. 
colección de sus artículos publicados en distintos medios de prensa, tanto españoles como cubanos, a lo largo de los años. Este es el material que se ha conservado en el Convento de los Carmelitas Descalzos de Toledo y que tuve ocasión de consultar en mi visita del otoño de 2017 con que daba comienzo al presente artículo. Se trata, por tanto, de materiales de una doble naturaleza, reunidos en sendos volúmenes mecanografiados. Para poder explicar su origen y su sentido hay que avanzar por un momento en la narración del devenir vital del P. Eusebio, hasta llegar a su ya adelantado destino trágico. En él ocupará un lugar central la ciudad de Toledo, que ahora guarda y custodia la memoria escrita del sacerdote carmelita, quien sintiera la vocación religiosa a la temprana edad de trece años, abrazando ya la senda iniciada por sus hermanos mayores. Llevado por sus padres al Colegio de Aspirantes Carmelitas Descalzos de Medina del Campo (Valladolid), va a iniciar allí un largo y sacrificado periodo de formación. En Medina del Campo concluirá sus primeros estudios y, una vez confirmada la fortaleza de su vocación, será trasladado al noviciado de Segovia, junto al "sepulcro glorioso de San Juan de la Cruz; allí "según explicará su hermano" tomó el hábito el día 24 de octubre de 1903, cambiándole el nombre de pila de Ovidio, como se acostumbraba en la religión y los apellidos de familia; le pusieron entonces el nombre de Eusebio $^{27}$ del Niño Jesús, y el 25 del mismo mes del año siguiente hizo su profesión de votos simples a manos del P. Miguel de la Sagrada Familia, que era el prior"28.

\section{EN TOLEDO SE CUMPliRÁ SU DESTINO}

A continuación, y antes de profesar solemnemente, el joven Ovidio Fernández Arenillas es enviado a Toledo para estudiar Filosofía. Sin él saberlo, se está empezando a trazar un círculo que tiene como principio y final la antigua ciudad que albergara la Escuela de Traductores del Rey

27 Quizás para esta elección pudiera haber influido el que dos días antes, el 22 de octubre, la Iglesia celebra en su santoral a San Eusebio Mártir, que junto con Felipe, Severo y Hermes, fueron encarcelados, torturados y posteriormente consumidos en la hoguera en Adrianópolis de Tracia, en época de Juliano Apóstata (http://martirologioromano1956. blogspot.com/2013/02/octubre-22.html [Consultado el 20-11-2019).]

Valentín de San José, op. cit., p. 115. 
Sabio. En efecto, el lugar inicial donde recaló tras sus primeros votos habrá de ser también el lugar en el que derramaría su sangre. En efecto, tras un periplo incluso trasatlántico sobre el que luego volveremos, el P. Eusebio sería destinado a Toledo en mayo de 1933, como subprior y maestro de estudiantes, para convertirse ya a partir del mes de mayo de 1936 en prior de la Comunidad ${ }^{29}$. Precisamente toda la trayectoria de esos ańos finales se puede seguir con numerosos datos personales y en ocasiones escalofriante detalle a través de este extenso epistolario con su querido hermano Valentín de San José ${ }^{30}$, a quien confiesa reiteradamente su preocupación por la extrema situación de crisis que vive el país. Así, por ejemplo, en la carta fechada el 22 de febrero de 1936 le habla con pesadumbre y temor del ambiente incierto, que no puede por menos que hacerle albergar negros presagios: "Ya convendréis la fecha, si el Señor detiene la marcha hacia el abismo" ${ }^{31}$. Y a continuación, manteniendo la habitual tónica de unión familiar que lo caracterizará siempre, añade, aludiendo a la lógica desazón que, ante la aciaga situación del país, intuye que acongojaría a sus hermanos: "De los hermanos nada he sabido, supongo estarán buenos aunque no tranquilos" 32 .

Esos negros presagios, en efecto, se cumplirán al paso de tan solo unos pocos meses, cuando la Guerra Civil arrase con todo y divida abruptamente vidas, legados y patrimonios. En el caso concreto de Toledo, tras sumarse a la rebelión el coronel José Moscardó, director de la Academia de Infantería, este proclamó el 21 de julio de 1936 el estado de guerra, apoderándose de la ciudad. Sin embargo, el gobierno legítimo de la República enviará al día siguiente una nutrida columna que, al mando del general Riquelme, logrará hacerse con el control urbano, ocasionando el encierro de los sublevados en el Alcázar, lo que dará así inicio al largo asedio que iba a adquirir tintes simbólicos para ambos bandos, hasta que a finales de septiembre las tropas de refuerzo del ejército rebelde logran tomar la ciudad. Pero durante los dos meses que duró el sitio, las calles de Toledo (como tantos otros lugares de uno y otro signo en ese sangriento paréntesis que se abre en España entre 1936 y 1939) serán escenario de numerosas atrocidades, que, en este

\footnotetext{
29 José Vicente Rodríguez, op. cit., 2007, pp. 64 y 69.

30 Proceso de Beatificación, I, op. cit., pp. 1-76.

31 Ibidem, p. 75.

32 Ibidem.
} 
caso, van a tener como víctimas principales a los religiosos. De este modo, tanto sacerdotes como frailes o monjas serán encarcelados o directamente asesinados. Como claro símbolo de ese ciego fanatismo, que exacerba lo peor de un anticlericalismo que venía ya con auge larvado desde las últimas décadas del siglo XIX y que aniquila buena parte del patrimonio artístico atesorado en iglesias y conventos durante siglos, se erigiría en Toledo la destrucción de la imagen del Cristo de la Vega, protagonista, como es bien sabido de una famosa leyenda de José Zorrilla, y que quedará reducido a más de cuarenta trozos de astillada madera.

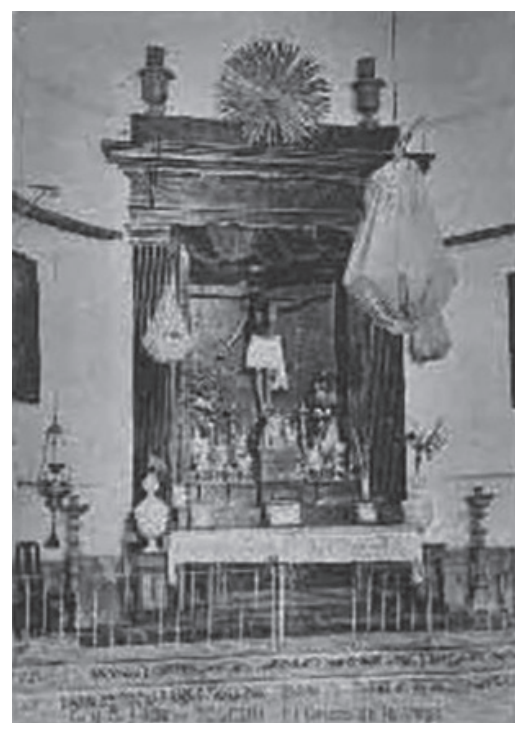

Cristo de la Vega

En ese contexto de persecución que sufren clérigos y órdenes religiosas ${ }^{33}$, de un total de veintidós frailes que se hallaban en el Convento de los Carmelitas Descalzos morirán nada menos que dieciséis, comenzando por su prior, el P. Eusebio del Niño Jesús. El P. Valentín de San José recoge los últimos momentos de la vida de su hermano, quien, como responsable máximo de su Comunidad, organizó el refugio de cada uno de los frailes

33 Como relata pormenorizadamente y con abundancia de datos — si bien de manera bastante sesgada - Jorge López Teulón, en su Toledo 1936, ciudad mártir, Madrid, Edibesa, 2008. 
en casas de familias de toda su confianza. La mayoría, no obstante, fueron localizados y asesinados sin miramientos. Y así sucedió con el P. Eusebio del Niño Jesús, quien aceptó cobijarse con los Rodríguez Bolonia, “donde habían guardado también gran parte de los ornamentos de la Iglesia" ${ }^{34}$. Sin embargo, al parecer alguna delación condujo a los milicianos en la tarde del 22 de julio de 1936 a la casa de dicha familia, encontrando tan solo en ella a las mujeres. Eusebio, al escuchar las voces, y temiendo que las amenazas proferidas contra sus anfitrionas se concretaran en ataques, se entregó directamente. Al salir a la calle, no le dieron tiempo más que a doblar la esquina, cuando "le hicieron una descarga y allí cayó bañado en su propia sangre" 35 .

El mismo destino corrieron sus otros quince compañeros, salvándose tan sólo seis de los frailes de la Orden. Significativamente, los daños sufridos en del Convento de Carmelitas Descalzos no se limitarán a las vidas abruptamente segadas, sino que también incluye -entre otros menores - su monumental biblioteca, que albergaba unos treinta mil volúmenes, que sería pasto de las llamas y ardería hasta sus cimientos; hasta el punto de que, donde antes se levantaba dicho refugio del saber, ahora se levanta una huerta-jardín ${ }^{36}$. La ciencia ha dejado paso a la Naturaleza, bien que el origen de esta metamorfosis resultara de todo punto dramático.

Pasado el tiempo, y consideradas las circunstancias violentas en que habían muerto estos dieciséis carmelitas descalzos, la Orden optará por iniciar el complejo proceso para que fueran considerados mártires de la religión, y por ese motivo, beatificados. Por tanto, el 30 de octubre de 1962 se constituyó el Tribunal Diocesano que habría de instruir dicho proceso, que culminará el 11 de septiembre de $1965^{37}$, con la toma de declaración a cincuenta testigos. A partir de ahí se inicia un largo plazo de recogida de materiales, testimonios y documentos, que se plasmará inicialmente en los mencionados dos extensos volúmenes mecanografiados que se conservan

34 Valentín de San José, op. cit., p. 126.

35 Ibidem.

36 Ibidem, 124-127 y José Vicente Rodríguez, op. cit., 2007, pp. 345-350.

37 Monseñor José Luis Gutiérrez, "Presentación", en Congregatio de Causis Sanctorum P. N. 1078 Toletana Beatifictionis seu Declarationis Martyrii Servorum Dei Eusebii a Iesu Infante et XV Sociorum. Positio Super Martyrio, Roma, Tipografia Guerra, 1995, p. 1. 
actualmente en el Convento de Toledo, a cargo del Vicepostulador de la Causa, el propio P. José Vicente Rodríguez, a cuya amabilidad infinita debo el haberlos podido consultar. En ellos, y mediante la certificación del notario don Apolonio Serrano Ruiz (Notarius Actuarius, Toletium), que firma y sella las páginas de ambas obras, y rubrica la autenticidad de cualquier mínima modificación o corrección introducida en el texto mecanoscrito, dando fe de la exactitud y autenticidad de todos los materiales allí recogidos, se reúnen el Epistolario de los dieciséis carmelitas, en un primer volumen de doscientas veinticinco páginas, y los Escritos varios de los mismos, en un segundo, que consta de doscientas cincuenta y siete páginas. Todo ello bajo el título global de Proceso de Beatificación de los Mártires Carmelitas Descalzos de Toledo. Escritos. Ninguno de los volúmenes lleva escrita fecha alguna, debiéndose suponer que fueron fruto del ímprobo trabajo de largos años, hasta lograr reunir textos de diversos autores, diferente naturaleza y orígenes geográficos muy lejanos, puesto que, en especial en el caso del P. Eusebio (que es de quien mayor número de aportaciones se recogen en uno y otro volumen) se recopilan incluso sus numerosos trabajos publicados en la prensa cubana durante los años en que estuvo allí destinado.

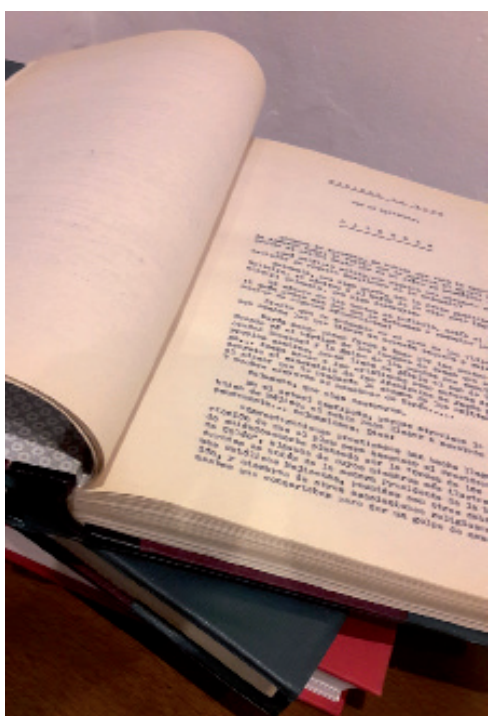

Volúmenes del Proceso de Beatificación de los Mártires Carmelitas Descalzos de Toledo. Escritos 
Avanzando en el largo procedimiento, se llega a la redacción y publicación en 1995 del volumen editado en Roma con la Positio ${ }^{38}$, es decir, con la documentación que avala las pruebas de solicitud de la beatificación, bajo el título de Congregatio de Causis Sanctorum P. N. 1078 Toletana Beatifictionis seu Declarationis Martyrii Servorum Dei Eusebii a Iesu Infante et XV Sociorum. Positio Super Martyrio (Congregatio de Causis Sanctorum, 1995) ${ }^{39}$, escrito íntegramente en latín, con excepción de la "Presentación", a cargo de Monseñor José Luis Gutiérrez, "Relator de la Causa", donde explica que se contienen aquí las pruebas del martirio sufrido por los dieciséis carmelitas y detalla minuciosamente todo el proceso legal y administrativo seguido hasta la fecha. Un ejemplar de dicha obra se ha conservado igualmente en el Convento de Carmelitas Descalzos de Toledo. La obra se presenta encabezada por la reproducción de un gran azulejo formado por cuatrocientas quince piezas de cerámica que hermosea la Iglesia del Convento y que representa a los dieciséis carmelitas, acogidos por la Virgen del Carmen. La obra artística está firmada por "José Aguado Villalba, Académico Numerario de la Real Academia de Bellas Artes y Ciencias Históricas de Toledo y profesor de

38 En el ámbito eclesiástico, y en términos generales, la positio viene a ser un escrito en el que se expone un asunto para solicitar o pedir algo. Pero como se especifica en Lexicon Canonicum: "En la curia romana, el uso del término positio incluye también la documentación que sostiene lo que se expone, los informes de las personas que lo estudian y los votos de los consultores. El uso más conocido del término es el de la positio en las causas de beatificación y canonización de los fieles, que tratan sobre las virtudes y fama de santidad o martirio, y sobre el milagro". (http://www. lexicon-canonicum.org/materias/causas-de-los-santos/positio/ [Consultado el 1711-2019]). Y añade la precisión de que a partir de 1983 cambió la normativa al respecto, por lo que, desde esa fecha -lo que incumbe al presente caso-, una positio "contiene habitualmente: la presentación del relator, la informatio (historia de la causa, las fuentes, biografía documentada, estudio teológico sobre la heroicidad de las virtudes; en el caso del martirio, más brevemente, se incluye la vida del Siervo de Dios, el martirio material y el martirio formal), y el summarium (decreto de validez del proceso, sentencia de non culto, las declaraciones de los testigos y los documentos; en la positio de milagros hay también una cronología de los hechos, dos votos de médicos ex oficio y la decisión de la consulta médica)" (Ibidem).

39 Congregatio de Causis Sanctorum P. N. 1078 Toletana Beatifictionis seu Declarationis Martyrii Servorum Dei Eusebii a Iesu Infante et XV Sociorum. Positio Super Martyrio, Roma, Tipografia Guerra, 1995. 
cerámica en la Escuela de Artes Aplicadas y Oficios Artísticos de la misma Ciudad Imperial" $"$.

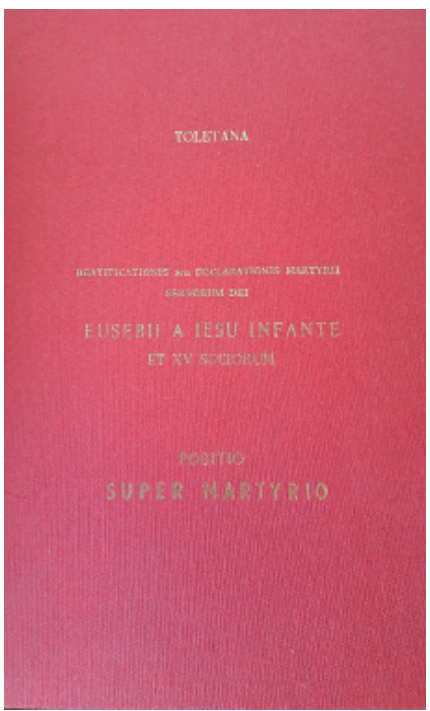

Cubierta del libro Congregatio de Causis Sanctorum P. N. 1078 Toletana...

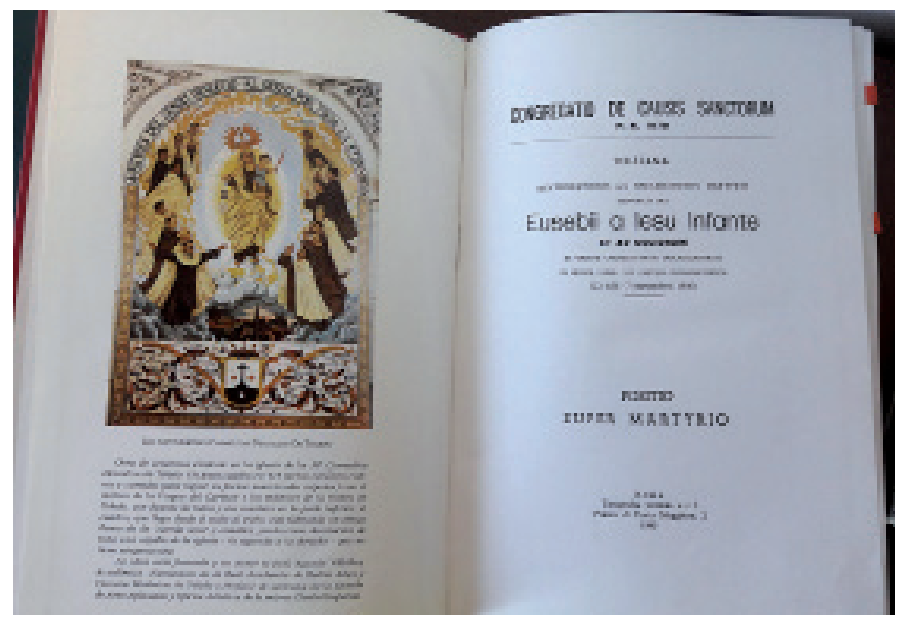

Página de dicho libro que reproduce el azulejo con los Mártires Carmelitas

40 Ibidem, en la portadilla. 


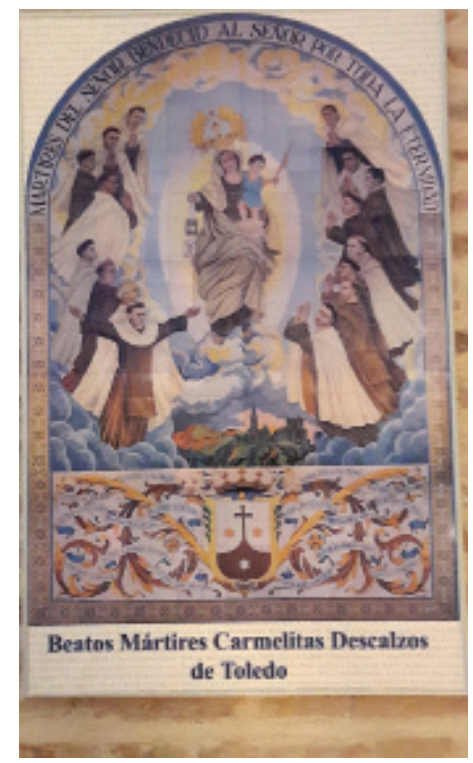

Azulejo en la Iglesia del Convento de los Carmelitas Descalzos de Toledo

Aún tardaría doce años en alcanzarse el fruto de tan extenso y complejo proceso, pero finalmente el 28 de octubre de 2007, el Cardenal Saraiva Martins beatificaba en la Plaza de San Pedro a los dieciséis carmelitas descalzos, incluyendo, claro está, al P. Eusebio del Niño Jesús.

La mencionada biblioteca que ardiera pasto de las llamas y de la que nada pudo salvarse contenía, entre otras muchas joyas, las obras del $\mathrm{P}$. Eusebio, tanto las ya publicadas, como otras que, inéditas en ese momento, fueron condenadas a permanente desaparición. Pero ¿̇cuál había sido la producción escrita de este culto sacerdote hasta su muerte prematura a los cuarenta y ocho años? ¿Cuál su trayectoria intelectual y literaria?

\section{El P. Eusebio del Niño Jesús: Labor literaria e intelectual}

Para responder siquiera parcialmente a estas preguntas, volvamos nuevamente atrás en el tiempo, y prosigamos con su devenir biográfico en el punto en que quedó interrumpido, esto es, tras su primera estancia en Toledo, después de sus votos iniciales y como estudiante de Filosofía, unos estudios que iba a continuar después en Ávila, donde hizo su 
profesión solemne el 3 de noviembre de 1907. Allí comenzaría también los cursos de Teología, para pasar a continuación a Salamanca, periodo en el que tendría la suerte de poder retomar el contacto directo con parte de su familia, ya que se dieron dos afortunadas casualidades: por un lado, su hermano mayor, Atanasio, estaba en esos momentos destinado en el mismo convento al que él llegaba ${ }^{41}$. Pero además, su hermana Genoveva había entrado poco tiempo atrás en el convento de las Carmelitas Descalzas de la misma ciudad. En una familia como se ha comentado ya reiteradamente de lazos tan estrechos conviene señalar la importancia que este hecho podría tener para el joven Eusebio, sobre todo teniendo en cuenta que en estas fechas las reglas conventuales eran tan rígidas que incluso impedían a los religiosos asistir al lecho de muerte o al funeral de familiares directos. Así lo iba a padecer incluso él mismo, al verse obligado a sufrir el dolor de no poder acudir siquiera a las exequias de su madre, Catalina Arenillas, fallecida en diciembre de 1908. En ese contexto cobra mayor relevancia la anécdota que relata con emoción su hermano Prisciliano (futuro Valentín de San José), al narrar cómo ambos, que se habían despedido en el pueblo siendo Prisciliano de muy corta edad, y sin haber tenido ocasión de volverse a encontrar, conciertan una cita fugaz en la estación de tren de Medina del Campo, donde el menor se encuentra ya como aspirante a carmelita. El mayor tenía que hacer allí un transbordo en su viaje desde Ávila a Salamanca. Según indica, "mejor que reconocerse, se conocieron, pues uno y otro tenían borrada la imagen formada, y uno y otro estaban completamente cambiados; en la estación se saludaron un ratito, de tren a tren; seguramente que ni en uno ni en otro se volvió a borrar aquel encuentro ni la impresión recibida” ${ }^{42}$.

Eusebio del Niño Jesús finalizaría sus estudios de Teología en Toledo, donde fue nuevamente trasladado y, por fin, "se ordenó de sacerdote en la capilla pública del palacio arzobispal el 21 de diciembre de 1912" "43, tras de lo cual ejercerá breves destinos en Salamanca y Medina del Campo, donde sería subdirector del colegio de aspirantes, así como confesor de las Hermanitas de los Ancianos Desamparados, quienes, según testimonio

41 José Vicente Rodríguez, op. cit., 2007, pp. 33-34.

42 Valentín de San José, op. cit., p. 116.

43 José Vicente Rodríguez, op. cit., 2007, p. 34. 
de su hermano menor, lo apreciaban enormemente ${ }^{44}$. Durante esos años tendrá numerosas ocasiones de gozo y satisfacción, tanto espiritual como familiar; pero también algunos momentos especialmente dolorosos, como cuando tuvo que asistir a su hermano Atanasio en el trance de su muerte, el 11 de marzo de 1915, tras regresar muy enfermo de Cuba ${ }^{45}$. Y sin embargo precisamente es a la llamada perla de las Antillas donde él mismo va a ser destinado a mediados de 1917, a pesar de los reiterados temores que manifiesta a sus superiores en torno a los riesgos que el clima caribeño puede suponer para su salud; temores probablemente acuciados por haber visto el efecto que ocasionó sobre su hermano mayor. Con todo, allí partirá; y a pesar de sus iniciales reticencias, conviene seńalar que su larga estancia en la isla resultaría determinante en su complementaria vocación como escritor, además de que, de nuevo el destino uniría al otro lado del charco a los hermanos Fernández Arenillas; no solo a Ovidio y Prisciliano (Eusebio del Niño Jesús y Valentín de San José), sino también a su hermana Efigenia, tal y como se tuvo ocasión de adelantar. Asimismo, curiosamente se va a encontrar durante esos años en Cuba también su hermano Ursicino, el único de los varones que no había entrado en religión, por lo que cabe suponer que emigraría a tierras americanas en busca de fortuna. De este modo, en las cartas escritas desde Cuba a su hermano Valentín de San José se encuentran diversas alusiones a Ursicino, a quien en agosto de 1926 localiza en La Habana, preocupado porque se encontraba éste sin trabajo ${ }^{46}$. No obstante, parece que la suerte comenzaría a sonreírle algunos meses después, ya que, a finales de noviembre de ese mismo año, Eusebio informa de que "Los hermanos parece están buenos. Ursicino sigue en La Habana, algunas veces va por El Carmen" ${ }^{7}$.

44 Valentín de San José, op. cit., p. 117.

45 Ibidem, p. 118.

46 Proceso de Beatificación, s. f., I, op. cit., p. 5.

47 Ibidem, pp. 8-9. 


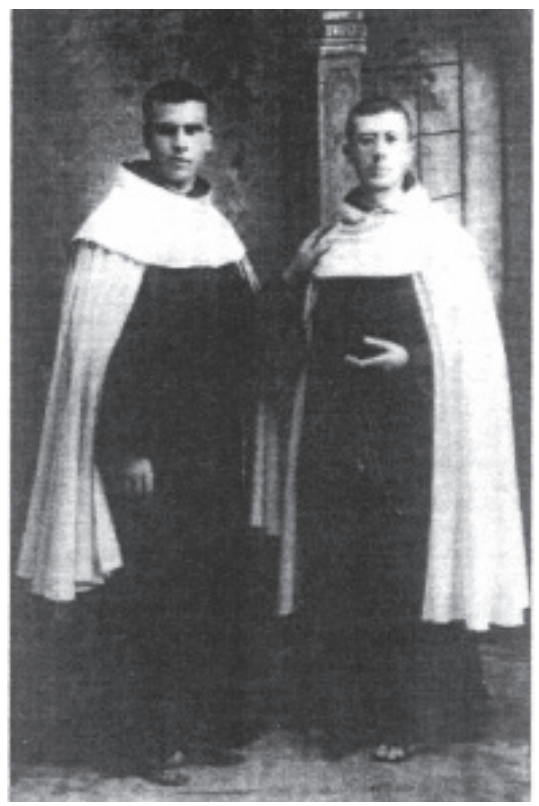

Foto de ambos hermanos, Valentín de San José y Beato Eusebio del Niño Jesús (dcha.)

La Orden de Carmelitas Descalzos no llevaba demasiado tiempo instalada en Cuba, puesto que su primera fundación, que tuvo lugar en La Habana, data de 1880, para extenderse en los años siguientes a otras localidades, como Camagüey, Matanzas, Sancti Spíritus o Ciego de Ávila. El P. Eusebio del Niño Jesús encontraría su primer destino en Matanzas, una ciudad situada al norte de la isla, que destacaba por su amor a la cultura, y en cuyo pequeño convento carmelita, fundado poco más de veinte años atrás, en 1894, pudo llevar una vida tranquila y sosegada. En opinión de su hermano menor, se trataba de "un conventito recogido y de poco bullicio, muy apto para su espíritu. El culto era relativo en aquella sociedad poco piadosa y muy superficial en general, aunque con almas muy fervorosas, pero relativamente pocas" 48 .

No duraría allí demasiado tiempo, pues apenas un año después de su llegada es trasladado a Sancti Spíritus, una de las localidades más antiguas de Cuba, situada en el centro de la isla, y donde se vería obligado a asumir las competencias de la administración de una de las parroquias más

48 Valentín de San José, op. cit., pp. 118-119. 
importantes, bajo la advocación de la Patrona de Cuba, que había sido encomendada a los carmelitas tan solo unos pocos años antes, en 1909. Se trata de la Virgen de la Caridad del Cobre, de arraigada devoción, en buena medida porque encarna de manera evidente el sincretismo religioso tan propio de la isla, ceñido en santería orisha a Oshun, una de sus principales deidades femeninas.

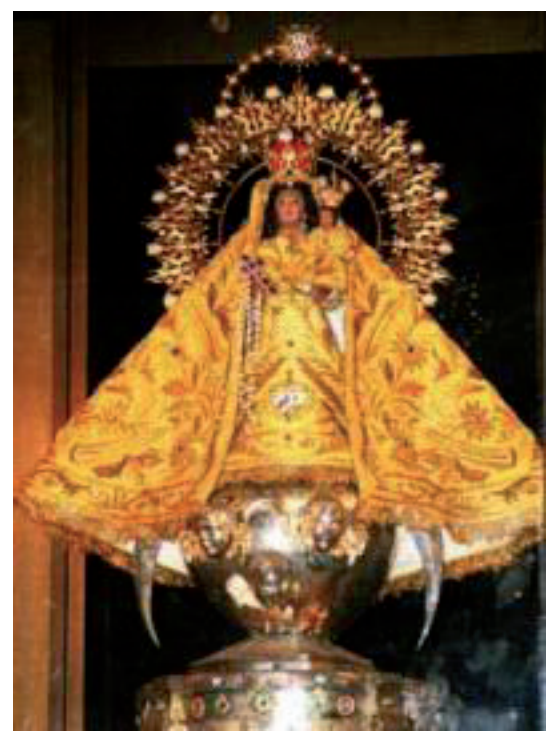

Virgen de la Caridad del Cobre de Sancti Spíritus

Las responsabilidades como párroco parecen resultar un tanto abrumadoras para alguien dotado de carácter sensible y con una salud que, en virtud de los diversos testimonios recogidos, parece haber sido un tanto frágil, y — según informa su hermano-, "no eran conforme a su espíritu y desasosegaban su alma" ${ }^{49}$. Por lo tanto, hacia finales de ese mismo año de 1918 sería destinado a la Habana capital. Allí tendrá la suerte de coincidir con su querido hermano menor, cabiéndole la suerte de poder encargarse el mismo Eusebio de la formación teológica de éste. Al parecer, se trató de una etapa en que supo ganarse el afecto y la simpatía de los fieles, hasta el punto de ser el religioso más solicitado tanto para predicaciones como para

49 Ibidem, p. 119. 
atender las confesiones de los penitentes. Sin embargo, el clima húmedo y caluroso de la ciudad, unido al excesivo trabajo, ocasionaron una serie de problemas de salud al P. Eusebio, que, aquejado de inapetencia y debilidad general, sufría con frecuencia de palpitaciones, lo que determinó a sus superiores a trasladarlo en octubre de 1920 a Camagüey, cuyo importante centro histórico y benigna climatología resultaron muy favorables para su restablecimiento.

Allí permanecería hasta marzo de 1927, en que tiene lugar su regreso definitivo a Espańa, significando ese periodo de seis años y medio una etapa muy fructífera en su trayectoria; no solamente ya en su primordial faceta como religioso, cuyo prestigio se afianza, sino en la otra complementaria, que es la que ocupa nuestro interés, y que parece que se le va a sumar desde este periodo, como es la de escritor. Como expliqué de manera muy resumida en el capítulo correspondiente de “Qué mandáis hacer de mí?". Una historia desvelada de relecturas teresianas en el contexto cultural de entresiglos, durante esta fecunda etapa Eusebio del Niño Jesús publicará toda una serie de obras, hoy en día rarísimas y difícilmente localizables, como La Madre de Jesús, ¿Inmaculada o no? Respuesta a un señor protestante (1922) $)^{50}$; Compendio biográfico del Padre Valencia. Religioso Franciscano ${ }^{51}$, editado en La Habana en 1926 y que aborda la figura de un célebre fraile español de la Orden de San Francisco que llegó a Cuba en 1800, donde adquirió fama de santidad hasta el punto de convertirse en reliquias los fragmentos de su hábito tras el momento de su muerte. Durante casi cuatro décadas dejó profunda huella - muy en especial, en la zona de Camagüey, al ocuparse de los leprosos del lazareto, que hasta entonces se encontraban abandonados y en condiciones miserables, además de llevar a cabo diversas labores fundacionales-. También vale la pena citar la

50 Solo conocemos estas dos obras a partir de las referencias que ofrece su hermano, Valentín de San José, op. cit., p. 122

51 P. Eusebio del Niño Jesús, Compendio biográfico del Padre Valencia. Religioso Franciscano, La Habana, Imp. Seoane y Fernández, 1926. Esta obra es la única de las publicadas durante su etapa cubana que se encuentra en la actualidad en varias bibliotecas de instituciones universitarias españolas. Además, pueden localizarse algunos ejemplares de su obra principal, Santa Teresa y el espiritismo (de la que enseguida nos ocuparemos), y en un par de bibliotecas también la edición del Comentario de Santa Teresa al Padre Nuestro, con prólogo del P. Eusebio del Niño Jesús (Madrid, Espiritualidad, s. f.). 
Historia del Niño Jesús de Praga en Camagüey. Conviene tener en cuenta que el Niño Jesús de Praga es una tradicional devoción carmelita, que se basa en la leyenda de que esta pequeña imagen, elaborada en cera, perteneció en su día a Teresa de Jesús, instaurándose luego la tradición de que pasaba de padres a hijos en la familia de los Condes de Treviño y Duques de Nájera, portadores del apellido Manrique de Lara. De este modo, en 1628 la princesa Polixena de Lobkowicz, que había recibido la imagen del Niño de manos de su madre, María Manrique de Lara como regalo de bodas, la donó a los Padres Carmelitas Descalzos de Praga. La imagen tuvo una historia llena de azares, y adquirió enseguida fama de milagrosa, la misma que ha mantenido hasta hoy. Como prueba de su arraigo en la Orden Carmelita, el P. Eusebio del Niño Jesús, no solo le dedicará la mencionada obra, sino que además se referirá a la imagen y a sus supuestas propiedades taumatúrgicas en artículos publicados en medios cubanos, como la revista Aromas del Carmelo. Además, y muy significativamente, cabría añadir que, tras su regreso de Cuba, el P. Eusebio tendrá una nueva oportunidad de demostrar su devoción por esta particular advocación de Cristo, al estar su nombre vinculado - según demuestra la documentación conservada - con la Cofradía del Niño Jesús de Praga en una localidad tan teresiana y carmelita como es Alba de Tormes, que, habiendo sido constituida canónicamente el 26 de diciembre de $1909^{52}$, alcanzó gran arraigo en toda la comarca. Así, Manuel Diego Sánchez, en su trabajo "Historia de Alba de Tormes: La Cofradía del Niño Jesús de Praga”, precisa que Eusebio del Niño Jesús firmó el libro oficial de dicha Cofradía el 26 de abril de 1930, en calidad de "visitador provincial" 53.

52 Según datos contenidos en el Libro de Registro de Socios (J-IV-2), conservado en el Archivo del Convento de los Carmelitas Descalzos de dicha localidad.

53 Manuel Diego Sánchez, "Historia de Alba de Tormes: La Cofradía del Niño Jesús de Praga”, Salamanca.AL DIA. es, 11 de diciembre de 2017 https://salamancartvaldia. es/not/166937/historia-alba-tormes-cofradia-nino-jesus-praga/ [Consultado el 2111-2019]. 


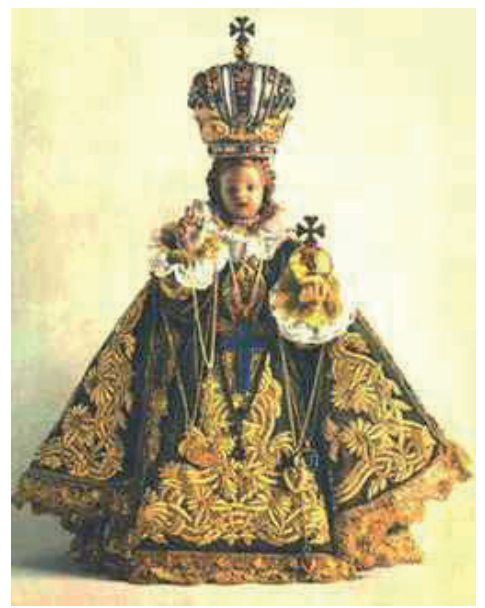

Niño Jesús de Praga

Pero no será tan sólo esta revista especializada la que recoja la firma del carmelita. Lo cierto es que durante estos años va a mantener una muy activa presencia en importantes medios de prensa locales y nacionales, como Camagüey Gráfico (donde poco antes, en torno a 1920, acaba de empezar a publicar sus versos el entonces muy joven, y futuro Poeta Nacional de Cuba, Nicolás Guillén, oriundo del municipio), revista donde Eusebio se ocultará bajo el seudónimo de El Solitario ${ }^{54}$; o en el diario El Camagüeyano (en el que precisamente Guillén ejerció como corrector de pruebas, para luego pasar a la redacción). Pero volviendo

54 A la hora de reunir el mayor número posible de artículos debidos a la pluma del P. Eusebio para el mencionado proceso de beatificación, se recopilaron todos estos firmados por "El Solitario", añadiendo el siguiente testimonio de autentificación: "A QUIEN PUEDA INTERESAR: El que suscribe: Manuel Ballina Inclán, vecino de Camagüey, Cuba, hago constar que fui redactor de la Revista Camagüey Gráfico constándome que los artículos firmados por el seudónimo de El Solitario son escritos por el Reverendo Padre Eusebio del Niño Jesús, Carmelita Descalzo; y que en muchas ocasiones el que esto suscribe recogía de manos del virtuoso carmelita los citados artículos y los entregaba en manos del Director señor Rafael Perón, el que por haber fallecido no ha sido posible la autenticidad de los mismos por él. Y para constancia firmo la presente, en Camagüey, Cuba, a quince de Febrero de mil novecientos sesenta y cuatro. Manuel Ballina Inclán // Terciario Carmelita” (Proceso de Beatificación, II: Escritos, p. 1)”. 
a la revista Aromas del Carmelo, se puede señalar que la fundó la propia Orden, en La Habana; y justamente en 1922, año en que se celebraba con grandes honores el tercer centenario de la canonización de Teresa de Jesús por parte de Gregorio XV. Y no va a ser, claro está, ninguna casualidad, que en torno a la celebración cubana de tamańa efeméride, a la que se referirá en varios de sus artículos de prensa, desempeñe un papel muy principal Eusebio del Niño Jesús, encargado por sus superiores de la difusión de los actos, además de personalmente muy motivado con la causa. Todos los artículos de su etapa cubana que pudieron ser localizados serían posteriormente recopilados y reproducidos en el ya mencionado volumen de Proceso de Beatificación de los Mártires Carmelitas Descalzos de Toledo. Escritos (s. f.), Volumen II: Escritos.

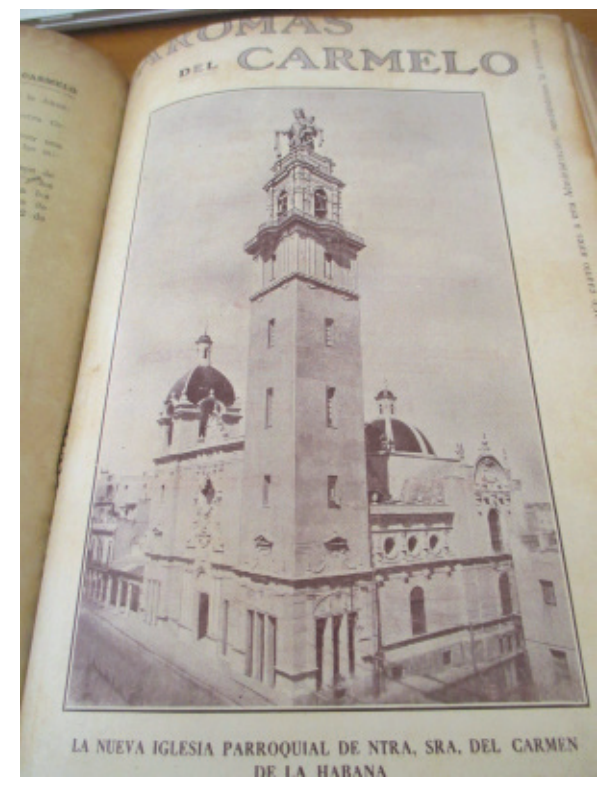

Revista Aromas del Carmelo (La Habana)

Conviene volver a recordar en este punto que al hilo de aquellas extensas pero también complejas cuatro décadas de conmemoraciones teresianas que alcanzaron su broche final en 1922, y que conllevarán la exaltación reiterada de la figura de la santa de Ávila, se llevarán a cabo también numerosas relecturas que podrían, sin duda, considerarse irrespetuosas, heterodoxas e incluso ofensivas desde las posiciones oficiales, por poner 
el acento en el cuerpo y no en el alma, en las exacerbaciones de los nervios y no en la entrega amorosa al Divino Amado. A este respecto, la Orden Carmelita Descalza, y en especial los más notables intelectuales de la misma, como es el caso del P. Eusebio del Niño Jesús, se aprestarán denodadamente a defender a su fundadora con todos los medios a su alcance.

Porque, en efecto, como un notable intelectual se puede considerar a Ovidio Fernández Arenillas, quien fue un sujeto preparada y de veras culto. De hecho, así lo describe Father Herrera en la semblanza que contiene el libro antes mencionado:

Con su sola presencia se hacía interesante a quienes por primera vez le trataban. [...] Muy trabajador y con un gran sentido de la responsabilidad de sus acciones, tanto de sacerdote como de religioso, había adquirido una formación muy sólida con un buen bagaje científico, incluso de conocimientos profanos, en el buen sentido de la palabra, que hacían de él un asceta y hasta un místico muy humano ${ }^{55}$.

A esos "conocimientos profanos", en algunas ocasiones — como se tendrá ocasión de observar, verdaderamente sorprendentes-, hay que unir, para el caso que nos ocupa, un significativo rasgo de su carácter, que viene dado porque supo mantener una postura abierta hacia aquellos que pensaban o creían de forma diferente, quizá porque, frente a la casi monócroma realidad que ofrecía la España de las primeras décadas del siglo, sus ańos caribeńos lo pusieron en contacto directo con concepciones religiosas sincréticas, prácticas de santería lindantes con la superstición y opciones espirituales divergentes. De hecho, según indica el subtítulo de su obra breve La Madre de Jesús, ¿Inmaculada o no? Respuesta a un señor protestante, y como confirma su hermano Valentín de San José, durante su larga estancia en Cuba se caracterizó por mostrarse accesible y dialogante, hasta el punto de que, al parecer, "le consultaban protestantes y espiritistas" 56 . Resulta significativo que su propio hermano, buen

55 Father Herrera O.C.D., "P. Eusebio del Niño Jesús (1888-1936)", Father HerreraValentín de S. José, op. cit., p. 27.

56 Valentín de San José, op. cit., p. 121. 
conocedor de la realidad cubana por haberla experimentado en primera persona, llamase la atención acerca de diversidad ideológica y religiosa con la que se tuvo que enfrentar Eusebio durante sus años antillanos, "pues sabido es lo mucho que allí abundan espiritistas y protestantes y la cantidad de ñáñigos que hay en los campos" ${ }^{37}$. Estos ñáñigos a los que alude Valentín de San José, constituían — de acuerdo con el estudio que les dedicaron Jorge Castellanos e Isabel Castellanos - una suerte de arraigada sociedad secreta, de carácter mágico-religioso, que "presenta curiosas similitudes con los misterios de la antigüedad grecorromana" 58 , caracterizándose por prácticas iniciáticas y sacrificiales, restricción de acceso (en este caso, a los varones de color), vinculación con la magia, establecimiento de tabúes, el recurso a la danza sagrada y la "presencia ineludible de un mito genésico" $" 59$. Su origen parece cifrarse en torno a la década de los ańos treinta del siglo XIX por parte de población esclava procedente de Nigeria.

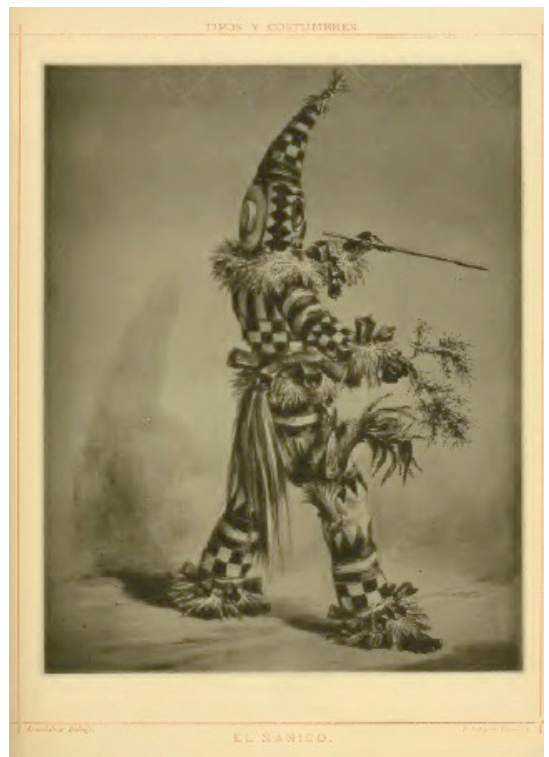

“El Náńigo”, Víctor Patricio de Landaluze, Tipos y costumbres de la isla de Cuba (1881)

57 Ibidem.

58 Jorge Castellanos e Isabel Castellanos, "La Sociedad Secreta Abakua: los ñánigos”, en Cultura Afrocubana, 1992, Miami, Universal, III, pp. 203-282 (p. 205).

59 Ibidem, p. 206. 
Ante tan heterogénea población, Eusebio del Niño Jesús demostrará ese carácter abierto, y propenso al diálogo con el otro. De hecho, Father Herrera, en su semblanza, destacará que "era buen psicólogo y se daba enseguida cuenta de las condiciones, excelencias y deficiencias de las personas que trataba" ${ }^{60}$; añadiendo que "además de muy buen religioso, era hombre de buen consejo"61. Todo ello parecería encajar con los testimonios que dejó por escrito su hermano, para quien no fueron pocos los que volvieron a la fe católica gracias al trato del P. Eusebio, admirando "su benevolencia y raciocinio" 62 . No obstante, este mismo hecho habría, al parecer, ocasionado una serie de ataques contra su persona. Perseverando, con todo, en la propensión hacia la tolerancia que siempre lo caracterizará, no parece que suscitaran en él respuesta alguna. Pero sin embargo, sí que reaccionaría de manera vehemente hacia lo que consideró un ataque intolerable hacia la sagrada fundadora de su Orden.

En lo que se refiere a los fuertes cimientos que hacia esas fechas había alcanzado ya un fenómeno como el espiritismo en Cuba — que parece, en efecto, haber constituido una de las mayores preocupaciones del $\mathrm{P}$. Eusebio- , se puede confirmar su arraigo en la isla mediante una somera revisión de las publicaciones periódicas españolas del ámbito espírita, pues en ellas se hace evidente la importancia de las Sociedades y Hermandades cubanas, la actividad desarrollada y la enorme implicación y contacto con el movimiento al otro lado del Atlántico. Un buen ejemplo lo constituye, precisamente, $\mathrm{La} \mathrm{Luz}$ del Porvenir ${ }^{63}$, revista fundada y dirigida durante casi veinte años por la ya aludida Amalia Domingo Soler.

De hecho, al parecer, la extensión y popularidad del fenómeno era tal que "era muy habitual, incluso entre personas bien católicas, asistir a las reuniones espiritistas. El Sr. Obispo de Camagüey, Fr. Valentín Zubizarreta, tuvo que escribir una carta pastoral afrontando el problema" ${ }^{4}$.

60 Father Herrera, op. cit., p. 28.

61 Ibidem.

62 Valentín de San José, op. cit., p. 121.

63 De hecho, la presencia constante de Cuba en la revista revela que los contactos eran habituales y muy fluidos. De este modo, se incluyen colaboraciones de hermanos cubanos, se informa de actividades espiritistas en la isla, se reproducen artículos de prensa locales, etc.

64 Manuel Bonet, "Bajo las sombras de las palmas cubanas", $2014 \mathrm{http} / / /$ santidadencuba. blogspot.com/2014/10/palmas-carmelitas-b-eusebio-del-nino.html?m=1 [Consultado 
Es en ese contexto doble —que conjuga los preparativos de la conmemoración del centenario teresiano con la expansión del fenómeno espiritista entre amplias capas de la población cubana- donde habría que situar el impacto de un hallazgo que desencadenará la escritura de la que, sin duda, será la principal obra literaria del P. Eusebio ${ }^{65}$, y cuyo origen él mismo relata. De este modo, cuando se hallaba en 1921 buscando una serie de obras científicas, la casualidad puso en sus manos, según nos explica, "un catálogo de libros de los más raros e imaginables que darse pueden" ${ }^{66}$, y de entre ellos va a sorprenderle, precisamente por lo llamativo del título, uno en concreto, que se apresuró a adquirir. Se trataba de Santa Teresa, médium, del ya mencionado José Blanco Coris, cuya lectura causó una fuerte impresión sobre su ánimo. Como carmelita, Eusebio del Niño Jesús entenderá como un terrible agravio contra su fundadora el libro —o "libelo", según él reiteradamente lo tildará- del pintor malagueño. Así, si su amor y admiración hacia Santa Teresa de Jesús lo llevaron a dedicarle numerosos artículos de los que había venido publicando hasta ese momento en la prensa periódica, ahora, guiado por su devoción emprenderá una tarea de mucha mayor envergadura: una suerte de cruzada contra lo que considera infamantes sospechas que las tesis espiritistas habían vertido sobre el nombre de la Santa de Ávila. De este modo, en una empresa acometida durante varios ańos en Cuba, pero culminada finalmente tras su vuelta a España, el P. Eusebio pone su pluma al servicio de una defensa que contrarreste la obra de pintor malagueño, pero también, de paso, la de su antecesora Amalia Domingo Soler, que,

el 24-08-2017]. En realidad, estas palabras pertenecen a un comentario del Blog titulado "Bajo la sombra de las palmas cubanas", escrito por Manuel Bonet el 20 de octubre de 2014, que procede de un lector que firma tan sólo como "Antonio Luis", y que escribe su texto el 21 de ese mismo mes. Pero lo cierto es que el propio Eusebio del Niño Jesús, en su obra Santa Teresa y el espiritismo menciona en diversas ocasiones al obispo Valentín Zubizarreta y su carta pastoral Instrucción sobre el espiritismo.

65 Se incluirá aquí tan solo un breve resumen, al constituir el objeto central del último capítulo de mi ya mencionado libro “¿Qué mandáis hacer de mi??". Una historia desvelada de relecturas teresianas en el contexto cultural de entresiglos, por lo que remito a las pp. 225-251.

66 P. Eusebio del Niño Jesús C. D., op. cit., 1929, p. 1. 
aun siendo de mucha mayor entidad y superior calado, sin embargo, el carmelita percibía como menos peligrosa, al juzgarla de ficción. El motivo es que, mientras que la obra de Blanco Coris coloca el foco directamente sobre la Doctora Mística desde su mismo título, asociándola con unas supuestas cualidades mediúmnicas, la de Amalia Domingo contiene las revelaciones, presuntamente obtenidas a través de un médium, a lo largo de más de dos años de sesiones por un espíritu que, para cualquier lector avisado, se identifica a las claras con Teresa de Jesús, pero que en el texto se presenta bajo el criptónimo de "Iris". Este particular permite al P. Eusebio descartarlo como volumen teórico, relegándolo al terreno de la ficción, de modo que lo va a considerar una "utópica novela" 67.

La obvia intención de desagravio con que el P. Eusebio concibe su trabajo queda de manifiesto, entre otros aspectos, en una carta que envía desde Medina del Campo el 13 de febrero de 1929 a su hermano Valentín de San José, donde, además de reflejar diversos detalles acerca de la publicación, aludiendo a la propia Doctora Mística, le confiesa su deseo de que "quiera Ella darla [sic] buena acogida para su gloria y para bien de la Orden" 68 .

El carmelita dedicará varios años de ardua labor al acopio de fuentes, documentación y denodadaslecturas, básicamente dela principal bibliografía existente en el momento acerca del movimiento espírita, que lo llevará a la escritura final de su magno Santa Teresa y el Espiritismo, dividido en dos volúmenes, de casi quinientas y casi setecientas páginas respectivamente. La vehemencia de su defensa teresiana, junto con el exhaustivo y exigente concepto de lo que implica una obra de esta naturaleza, contribuirán, sin duda, a tal abundancia de páginas. Pero tampoco se puede perder de vista que, como explicará después Father Herrera, el P. Eusebio

ciertamente no tenía el don de la síntesis, como se notaba enseguida en sus prédicas y conferencias, siempre largas, pero no se hacía pesado ni se repetía, gracias a lo bien que dominaba el asunto y a su espíritu analítico, que le hacía ver muchos matices interesantes en materias áridas ${ }^{69}$.

67 Ibidem, p. 3.

68 Proceso de Beatificación, I, op. cit., p. 23.

69 Father Herrera, op. cit., p. 28. 
Si bien se puede considerar Santa Teresa y el espiritismo una obra que no solo tiene su origen germinal en la isla de Cuba, sino que allí fue planeada y redactada, con la intención cierta de haber visto la luz en tierras caribeñas (como prueban sus preceptivos Nihil obstat al comienzos de la obra: el Imprimatur, firmado el 16 de junio de 1925 por el Obispo de Camagüey; y el Imprimi potest, firmado el 25 de abril de 1926 por fray José Vicente de Santa Teresa, Vicario Provincial de la Orden en La Habana), lo cierto es que una serie de circunstancias ajenas a la voluntad de su autor ocasionaron una larga demora en la publicación. En buena medida, se tiene conocimiento de que uno de los principales motivos estriba en que una adinerada devota que había prometido subvencionar la edición se retrasaba indefinidamente en materializar sus promesas, y así se lo hace saber a su hermano por carta, fechada en Camagüey el 24 de agosto de $1926^{70}$. Menos de nueve meses después, el P. Eusebio abandona Cuba para asistir en Segovia en mayo de 1927 al Capítulo Provincial de la Orden, lo que supuso su adiós definitivo a las tierras caribeñas, ya que en éste iba a ser nombrado director del colegio de aspirantes de Medina del Campo —denominado precisamente Colegio Teresiano-, a la vez que su hermano Valentín de San José resultaba elegido prior de Segovia. Por tanto, los trámites para la publicación de Santa Teresa y el espiritismo se reanudarán en España, donde finalmente los dos volúmenes que componen la obra global, titulados Mediumnidad teresiana y Puntos cardinales del espiritismo, verían la luz en 1929 y 1930, respectivamente.

Como puede comprobarse, el proceso iba a dilatarse considerablemente en el tiempo, encontrándose en el epistolario entre ambos hermanos diversas alusiones a los detalles del mismo, entre los que destacan los retrasos del prologuista, un ilustre experto en la figura de Santa Teresa, como era Bernardino de Melgar y Abreu, marqués de San Juan de Piedras Albas, quien daría a conocer a lo largo de su vida diversas epístolas y otros textos autógrafos de la autora abulense y de personajes relacionados con ella de manera muy directa (buena parte de ellos en el Boletín de la Real Academia de la Historia, a la que pertenecía); además de participar en los actos de conmemoración del tercer centenario de su canonización, organizados por la Real Academia de la Historia en Ávila el 15 de octubre de 1922.

70 Proceso de Beatificación, I, op. cit., p. 4. 
Pero comoquiera que en “Qué mandáis hacer de mi??. Una historia desvelada de relecturas teresianas en el contexto cultural de entresiglos ya comenté y analicé con detalle las características y contingencias que rodean a esta obra del P. Eusebio, además de insertarla de manera adecuada en la mencionada cadena de relecturas teresianas de entresiglos, remito al lector a las páginas correspondientes en dicho estudio ${ }^{71}$.

En cualquier caso, retomando su actividad tras la vuelta a España en mayo de 1927, se puede documentar que permanecería en la localidad vallisoletana de Medina del Campo hasta el Capítulo Provincial de abril de 1930 en Madrid, ocupando primero el mencionado puesto de director del Colegio de Aspirantes (o Colegio Preparatorio), para pasar luego a compatibilizar ese puesto con el de Superior de la Comunidad, en el Convento colocado bajo la advocación del Cuerpo de Cristo, que, fundado en 1645, tuvo que ser refundado el 3 de junio de 1891, tras el período en blanco que supuso la exclaustración asociada a la Desamortización de Mendizábal ${ }^{72}$. En dicho Capítulo de abril del 1930 se le va a trasladar como prior al convento de Ávila ${ }^{73}$, donde desarrollará una amplia actividad, pudiéndose destacar, además, que marcó profundamente a dos jóvenes, Aurelia de Miguel y Lucrecia Carrillo Terciaria Carmelita que parece haber sido amiga de Mercedes, la única hermana del P. Eusebio que no entró en la religión-, convirtiéndose ambas en sus hijas espirituales, hasta el punto de mantener un fluido y muy interesante epistolario que durará casi hasta el momento de su muerte, en el que se observa que, con tono cercano y cordial, pero también paternalista, el sacerdote las orienta, aconseja y hasta consuela cuando es menester ${ }^{74}$.

71 Amelina Correa Ramón, op. cit., 2019, pp. 225-251.

72 Óscar Ignacio Aparicio Ahedo, Los hijos de Santa Teresa en España, Burgos, Monte Carmelo, 2014, pp. 216-217.

73 José Vicente Rodríguez, op. cit., 2007, pp. 52-53.

74 Proceso de Beatificación, I, op. cit., 84-143 y 144-169. Para interesantes temas contenidos en este epistolario que se pueden poner en relación con preocupaciones propias de la época de entresiglos, como pueden ser los debates que asociaban la neurosis con los fenómenos místicos, o los posibles riesgos que podían producir los excesos de lecturas espirituales, como eran los textos teresianos de los que con cierta frecuencia se alertaba desde el estamento médico acerca de los riesgos, cf. Amelina Correa Ramón, op. cit., 2019, pp. 249-250. 
En Ávila residirá hasta que en mayo de 1933 fue enviado al que —iquién podría saberlo entonces...! - iba a ser su destino final: el convento de Toledo, donde llega inicialmente como subprior y maestro de estudiantes, y a partir de mayo de 1936, ya como prior $^{75}$. Disfrutamos de ocasión única de seguir de manera dinámica y vivaz la intensa trayectoria de esos nueve años desde su regreso de Cuba gracias al epistolario con su querido hermano Valentín de San José, por el que se deslizan habitualmente numerosos datos y detalles, así como indicios que reflejan de modo elocuente atributos de su personalidad (por ejemplo, la cordial relación que, sorprendentemente, acabó entablando con el pintor y escritor espiritista cuya obra tanto le había escandalizado, José Blanco Coris) ${ }^{76}$.

Pero además, durante este periodo, como cabía esperar, va a continuar su intensa labor intelectual, colaborando con revistas especializadas, fundamentalmente, aquellas vinculadas con su Orden, como Glorias del Carmelo (editada precisamente por los Carmelitas Descalzos de Toledo, y donde publicará varios años antes de su llegada a la ciudad imperial, en concreto, entre 1927 y 1929), Mensajero de Santa Teresa y San Juan de la Cruz (Ávila), o la veterana El Monte Carmelo (Burgos), donde aparecen artículos de tema religioso, con muy diferente planteamiento u orientación. Cabe señalar, de hecho, que en la correspondencia con su hermano aparecerán alusiones a las tareas literarias que ocupaban su atención y resultan de su agrado, e incluso referencias a las etapas en que puede dedicar poco tiempo a las letras.

Pero la firma del P. Eusebio va a aparecer asimismo en algunos periódicos locales de Castilla, como el Diario de Ávila, donde se ocupará de manera especial de la que sin duda había sido su hija más ilustre, dedicándose a relatar el proceso del patronazgo de España que le fue otorgado en 1617, a glosar la procesión en honor de Teresa de Jesús que se celebra tradicionalmente en su rincón nativo cada 15 de octubre, e incluso a prestar atención a las esculturas que, salidas de la gubia de un imaginero tan insigne como Gregorio Fernández, adornan la Iglesia de la Santa, construida sobre el solar de lo que fuera en tiempos su casa familiar, y entre las que destaca, precisamente, la misma que cada año

75 José Vicente Rodríguez, op. cit., 2007, pp. 64 y 69.

76 Para este tema concreto, cf. Amelina Correa Ramón, op. cit., 2019, pp. 246-247. 
procesiona gloriosamente por las calles de la ciudad ${ }^{77}$.

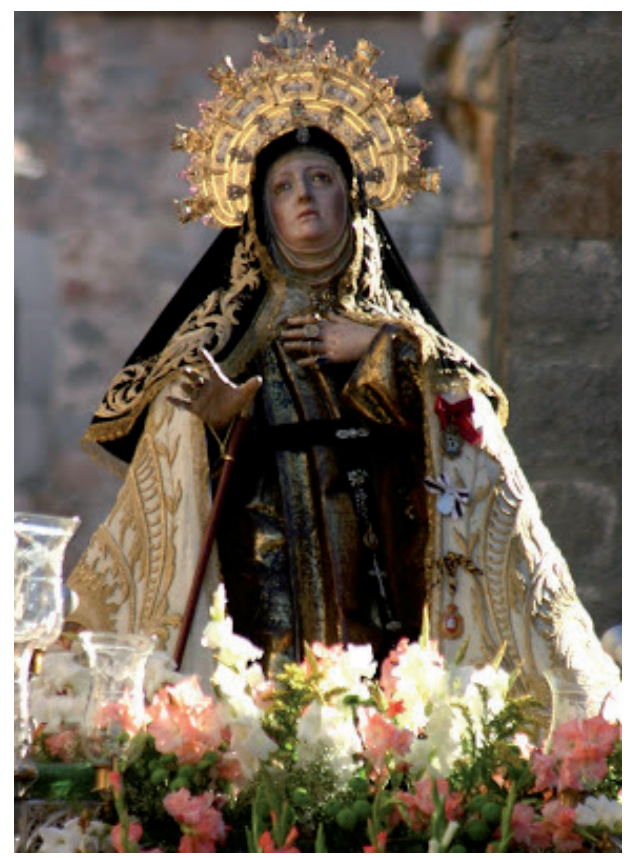

Santa Teresa de Jesús (Ávila), por Gregorio Fernández

La ardiente devoción que muestra el P. Eusebio del Niño Jesús hacia Santa Teresa se desliza en cada una de sus páginas, defendiendo vehementemente que

no hay ciudad como la de Ávila; no hay pueblo como el de España porque no hay mujer como Teresa, santa como la Reformadora del Carmelo, sabia como la doctora mística. Es Ávila la que posee la mujer más grande, la mujer más sabia, la mujer más santa ${ }^{78}$.

Cabe entender que, desde el punto de vista del perseverante y tenaz carmelita, la mujer más sabia, la más santa, la más grande, se hubiera visto atacada tiempo atrás (por José Blanco Coris, y antes, por Amalia

77 Proceso de Beatificación, II, op. cit., pp. 80-86.

78 Ibidem, p. 80. 
Domingo Soler), al ser puesta al nivel de los dudosos espíritus que se manifestaban en las mesas parlantes, al equiparar sus insignes cualidades que le valieron el título de Doctora Mística con las de la mediumnidad que convocaban a las voces de ultratumba y llenaban la salas de seguidores y curiosos, resultaba del todo intolerable. $\mathrm{Y}$ eso que en cuanto a reinterpretar el santoral católico en clave espiritista existían ya desde décadas atrás notorios antecedentes, como los reiterados y frecuentes que menudean por el Almanaque del Espiritismo, una publicación periódica de carácter anual (como es lo propio del género), aparecida en Madrid entre 1873 y 1875 . Puesto que en los almanaques al uso se da noticia del santo que preside cada día, en este caso se va a apelar a ellos, asociándoseles una serie de presuntas cualidades de tipo mediúmnico, relacionadas con los hitos de sus vidas y hechos portentosos. De este modo, se iba a considerar "médium escribiente mecánico" a san Toribio de Liébana, "médium intuitivo" a santa Genoveva o San Juan de Dios, "médium vidente" a santa María Egipciaca o san Cristóbal, "médium curandero" a san Lázaro, san Cosme y san Damián, y así un largo etcétera ${ }^{79}$.

Situada por el ámbito intelectual espiritista dentro de ese marco de reinterpretación simbólica y conceptual, el P. Eusebio se verá en la necesidad de rescatar a Santa Teresa de Jesús, devolviéndole su "voz más pura”. Y en ese contexto surgirá la que es, sin duda, su más importante y notable obra: Santa Teresa y el espiritismo, fruto de un trabajo ímprobo y de un enorme esfuerzo intelectual. Dicho empeño posibilitará que, aunque etiquetada mayoritariamente como texto religioso, y - tal y como se expresó al comienzo de este artículo- relegado casi de manera exclusiva a los estudios de ámbito teológico, la obra del P. Eusebio haya merecido también, en fechas recientes, consideración desde el punto de vista de la filosofía. De este modo, se constata que se le hace justicia tanto tiempo después de su muerte al encontrar su nombre incluido en la magna obra de Gonzalo Díaz Díaz, Hombres y documentos de la historia de la filosofía en España, que en forma de diccionario y en siete volúmenes fue publicando el Centro de Estudios Históricos del CSIC entre 1980 y 2003. Y en efecto, en el volumen III se recoge una breve entrada de

79 Almanaque del Espiritismo para 1873. Escrito con la colaboración de varios espiritistas, Madrid, Imprena de D. J. M. Alcántara, 1873, p. 12. 
nuestro carmelita, consignando cuatro obras que se podrían adscribir al campo de la filosofía ${ }^{80}$.

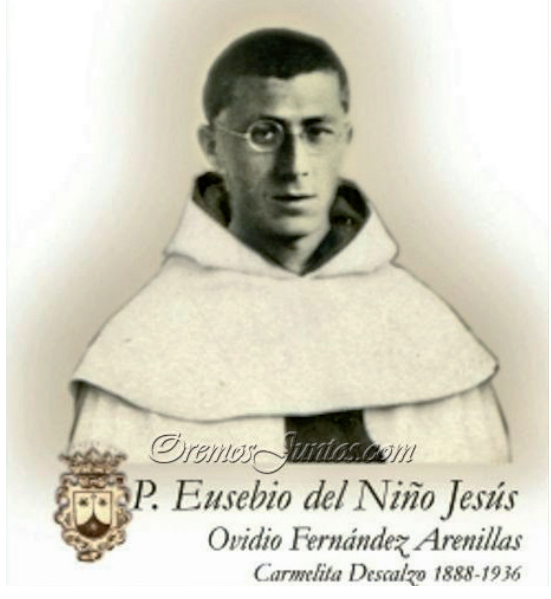

Retrato del Padre Eusebio del Niño Jesús

80 Gonzalo Díaz Díaz, Hombres y documentos de la historia de la filosofía en España, Madrid, Centro de Estudios Históricos del CSIC, 1988, vol. III, p. 92. 